\title{
Espécies de Parmotrema (Parmeliaceae, Ascomycota) do litoral centro-sul do Estado de São Paulo V. Grupo químico alectorônico ${ }^{1}$
}

\author{
MARCELO PINTO MARCELLI ${ }^{2}$ e MICHEL NAVARRO BENATTI ${ }^{2,3}$
}

(recebido: 15 de setembro de 2010; aceito: 06 de abril de 2011)

\begin{abstract}
RESUMO - (Espécies de Parmotrema (Parmeliaceae, Ascomycota) do litoral centro-sul do Estado de São Paulo V. Grupo químico alectorônico). O levantamento das espécies pertencentes aos gêneros de grandes parmélias do litoral centro-sul do Estado de São Paulo revelou a ocorrência de oito espécies de Parmotrema A. Massal. sensu stricto (talos foliosos de lobos arredondados em geral com mais de $0,5 \mathrm{~cm}$ larg. com margens inferiores não rizinadas) contendo ácido alectorônico como constituinte químico medular. São apresentados uma chave de identificação, descrições, comentários e ilustrações baseados em material brasileiro.
\end{abstract}

Palavras-chave - costões rochosos, liquens, manguezal, restinga

\begin{abstract}
Species of Parmotrema (Parmeliaceae, Ascomycota) of the central-southern coast of São Paulo State V. Alectoronic chemical group) In a survey of the species pertaining to genera of large parmeliae occurring in the coastal areas of the center-south coast of São Paulo State, Brazil, eight species of Parmotrema A. Massal. sensu stricto (foliose thalli with rounded lobes usually more than $0.5 \mathrm{~cm}$ wide with nude lower margins) containing alectoronic acid as main medullar substance were found. Identification key, descriptions, comments, and illustrations based on Brazilian material are provided for these species.
\end{abstract}

Key words - lichens, mangrove, restinga, rocky shores

\section{Introdução}

O gênero Parmotrema A. Massal. é caracterizado pelos lobos de ápices largos e arredondados (com mais de $0,5 \mathrm{~cm}$, muitas vezes ultrapassando 2 ou $3 \mathrm{~cm}$ de largura), ausência de pseudocifelas (aberturas no córtex com exposição de hifas medulares), ocorrência frequente de cílios marginais, ampla zona marginal do córtex inferior nua, rizinas geralmente simples, e ascósporos elipsóides de paredes espessas (Brodo et al. 2001, Nash $\&$ Elix 2002). Mais de trezentas espécies são conhecidas em todo o mundo (Nash \& Elix 2002), das quais mais de 90 são citadas para o Brasil (Marcelli 2004).

Todas as espécies apresentadas neste trabalho possuem como característica em comum a presença de ácido alectorônico medular, reconhecido em testes de coloração pela reação $\mathrm{KC}+$ róseo-avermelhada e pelo típico brilho verde azulado ("verde piscina") sob luz UV.

Aárea abrangida por esta pesquisa e seus respectivos dados geográficos, climáticos e de substratos encontrados na região são descritos em Benatti \& Marcelli (2009). Ela está localizada no litoral centro-sul do Estado de São Paulo, entre os municípios de Bertioga e Cananéia.

1. Parte da dissertação de mestrado do segundo autor, Programa de Pós-Graduação em Biodiversidade Vegetal e Meio Ambiente, Instituto de Botânica, SP, Brasil.

2. Instituto de Botânica, Núcleo de Pesquisa em Micologia, Caixa Postal 68041, 04045-972 São Paulo, SP, Brasil.

3. Autor para correspondência: michel_benatti@yahoo.com.br
Este trabalho objetivou realizar o levantamento, até então inexistente, das espécies de Parmotrema sensu stricto com ácido alectorônico medular que ocorrem nos diversos ambientes do litoral centro-sul paulista. São fornecidos chave artificial de identificação, descrições comentadas, dados das localidades e dos ambientes para as espécies encontradas.

\section{Material e métodos}

Foram analisadas amostras de coletas recentes e dos últimos 30 anos em todos os municípios da Baixada Santista localizados no litoral centro-sul do Estado de São Paulo, situados abaixo do trópico de Capricórnio e compreendidos entre Bertioga $\left(46^{\circ} 08^{\prime} 03^{\prime \prime} \mathrm{W}, 2^{\circ} 51^{\prime} 17^{\prime \prime} \mathrm{S}\right)$ e Cananéia

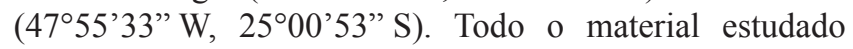
(exceto por alguns isótipos e parátipos que foram doados aos herbários B, G e ASU) encontra-se depositado no Herbário SP, do Instituto de Botânica em São Paulo.

A metodologia utilizada encontra-se descrita em Benatti \& Marcelli $(2007,2009)$. O material foi coletado e identificado conforme a metodologia em Fink (1905), Galloway (1985, 2007) e Hale (1979). Foram realizadas excursões pontuais de coleta a várias localidades urbanas e naturais de todos os municípios da região, tendo sido obtidas amostras de todos os ecossistemas costeiros que compõem a localidade de estudo, que foram acrescentadas às amostras obtidas nas últimas décadas.

A metodologia de análises químicas utilizadas seguiu Asahina \& Shibata (1954), Walker \& James (1980), White \& James (1985), Huneck \& Yoshimura (1996), 
Bungartz (2001) e Orange et al. (2001), com pequenas mudanças ou adaptações. Foram feitas análises por testes de coloração e por cromatografia em camada delgada (CCD) em solvente $\mathrm{C}$.

Embora sejam discutidos os aspectos mais relevantes pertinentes a cada uma das espécies identificadas, mais comparações e detalhes podem ser encontrados em Benatti (2005).

\section{Resultados e discussão}

No litoral centro-sul do Estado de São Paulo foram encontradas dez espécies de Parmotrema contendo ácido alectorônico. Embora uma parte delas já seja mencionada para São Paulo, há apenas dois trabalhos brasileiros contendo chaves e descrições para algumas poucas espécies deste grupo (Eliasaro \& Donha 2003, Spielmann \& Marcelli 2009), sendo parte delas em comum com as deste trabalho.

Uma espécie apresenta propagação direta por formação de isídios sorediados ou por formação apenas de sorédios (P. mellissii (Dodge) Hale). Todas as demais sete espécies encontradas têm reprodução apenas indireta, somente por formação de apotécios ( $P$. conidioarcuatum Marcelli, Benatti \& Elix, P. hyperlaciniatulum Benatti,
Marcelli \& Elix, P. maraense Hale, P. pycnidiocarpum Benatti, Marcelli \& Elix, P. restingense Marcelli, Benatti \& Elix, P. subrugatum (Nylander) Hale, e P. wainioi (A. L. Smith) Hale). Todas as espécies encontradas são corticícolas.

As espécies do grupo químico alectorônico que foram encontradas não têm a medula pigmentada de forma padronizada (como as espécies abordadas em Benatti \& Marcelli 2009b), porém é comum o surgimento de pequenas manchas aleatórias de pigmento alaranjado $\mathrm{K}+$ vermelho escuro ao menos em parte dos espécimes.

À exceção dos espécimes de $P$. mellissii, foram encontrados apotécios com ascósporos e picnídios com conídios em todos os demais materiais estudados.

Para todas as espécies descritas aqui, os testes de coloração do córtex superior são quase sempre $\mathrm{K}+$ amarelo (atranorina) e os da medula são $\mathrm{K}-, \mathrm{C}-, \mathrm{KC}+$ róseo (às vezes $\rightarrow$ alaranjado claro), $\mathrm{P}$ - e UV+ verde-azulado (ácido alectorônico). Parmotrema conidioarcuatum e $P$. pycnidiocarpum podem apresentar reações medulares $\mathrm{K}+$ fraco amarelado em alguns trechos, talvez devido à pequenas quantidades de atranorina. Há espécimes de P. mellissii que podem apresentar reações medulares $\mathrm{C}+$ amareladas.

Chave artificial de identificação para as espécies de Parmotrema contendo ácido alectorônico do litoral centro-sul do Estado de São Paulo

1. Talo isidiado e/ou sorediado, ocasionalmente com apotécios P. mellissii

1. Talo sem isídios ou sorédios, normalmente com apotécios

4. Margens densamente lacinuladas, lacínulas longas geralmente de vários milímetros a alguns centímetros de comprimento no mesmo talo, regulares e frequentes [talos jovens de P. subrugatum têm lacínulas curtas $\leq 3,0 \mathrm{~mm}$ compr., pouco desenvolvidas, sem estruturas papilóides]

5. Margem inferior uniformemente branca em todos os lobos, tornando-se marrom clara apenas num breve espaço de transição para a coloração negra do centro P. subrugatum

5. Margem inferior dos lobos geralmente marrom, tornando-se branca, creme ou variegada apenas abaixo de apotécios ou em lobos muito lacinulados

6. Lobos 8,0-18,0 mm larg., com pequenos "buquês" submarginais formados por aglomerações de lóbulos; ascósporos $c a$. 19,0-25,0 $\mu$ m compr.; conídios baciliformes comumente arqueados 5,0-7,5 $\mu \mathrm{m}$ compr. P. conidioarcuatum

6. Lobos 1,5-5,0 mm larg., sem ornamentações; ascósporos $c a$. 24,0-38,0 $\mu \mathrm{m}$ compr.; conídios unciformes 4,0-5,0 $\mu \mathrm{m}$ compr. P. hyperlaciniatulum

4. Margens inteiras a irregulares parcialmente sublacinuladas, lacínulas curtas em geral $\leq 3,0 \mathrm{~mm}$ compr., ocasionais e esparsas (margens apenas irregularmente sublacinuladas mesmo em talos grandes e desenvolvidos)

7. Lobos 1,5-3,5 mm larg.; picnídios restritos aos anfitécios e pedicelos dos apotécios, pedicelos geralmente muito inflados, de bases largas; pigmento alaranjado $\mathrm{K}+$ sempre presente, concentrando-se ao redor do himênio 
7. Lobos 2,5-6,0 (-11,0) mm larg.; picnídios apenas submarginais ou às vezes laminais; pedicelos pouco inflados, cilíndricos; pigmento alaranjado $\mathrm{K}+$ ausente ou presente, espalhado pela medula ou às vezes abaixo do himênio

8. Margens dos lobos frequentemente lacinuladas, apotécios denticulado-lacinulados, geralmente ciliados P. maraense

8. Margens dos lobos com lacínulas adventícias escassas a ausentes, apotécios lisos ou com lacínulas escassas, sempre eciliados

9. Ascósporos ca. 24,0-36,0 $\mu \mathrm{m}$ compr.; conídios unciformes curtos $c a$. 4,0-5,0 $\mu \mathrm{m}$ compr. P. restingense

9. Ascósporos $c a$. 16,0-25,0 $\mu \mathrm{m}$ compr.; conídios curto-filiformes $c a$. 5,0-7,5 $\mu \mathrm{m}$ compr.

P. wainioi

Parmotrema conidioarcuatum Marcelli, Benatti \& Elix, Mycotaxon 115: 74. 2011.

Figuras 1, 2

Talo lobado a sublobado, cinza esverdeado claro a cinza pardo quando em herbário, de até $23,0 \mathrm{~cm}$ diâm., subcoriáceo, ramulícola. Lobos de ramificação irregular, (3,5-) 8,0-18,0 mm larg., amontoados, de pouco a muito elevados, geralmente soltos, os ápices subarredondados a irregulares e em parte tornando-se lacinulados, subplanos a subconvexos, as margens subcrenadas ou irregulares, subplanas a ascendentes conforme se tornam lacinuladas ou formam apotécios, subonduladas, incisas, lacinuladas. Superfície contínua a irregularmente quebrada, de lisa a rugosa. Lacínulas distribuídas por toda margem do talo, mais acentuadas no centro, simples quando jovens tornando-se irregularmente ramificadas, agudas ou truncadas, subcanaliculadas, ciliadas, 0,3$17,5 \times 0,2-2,3 \mathrm{~mm}$, lado de baixo geralmente branco, misturadas à aglomerações submarginais medindo 3,0-8,0 mm diâm. que formam "buquês" de pequenos lóbulos ciliados, espalhados por todo o talo. Máculas distintas, puntiformes a lineares, geralmente nos anfitécios e pedicelos, mais raramente fracas e laminais. Cílios negros, simples ou às vezes furcados, 0,4-4,5 $\times$ ca. 0,05 mm, abundantes, escassos somente nos ápices dos lobos, distribuídos por toda a margem. Sorais, pústulas e isídios ausentes. Medula branca, com manchas ocasionais de pigmentações alaranjadas $\mathrm{K}+$ avermelhado escuro espalhadas pela medula. Lado de baixo negro, lustroso, com áreas lisas a rugosas ou venadas, livres de rizinas quando não em contato com o substrato. Margem inferior marrom, tornando-se branca quando em lobos lacinulados ou com apotécios ou às vezes variegada, lustrosa, 1,0-8,0 mm larg., atenuada quando marrom, nítida quando branca, lisa a pouco rugosa, nua. Rizinas concoloridas, simples, furcadas ou irregulares, $0,10-2,30(-3,80) \times c a .0,05(-0,10) \mathrm{mm}$, frequentes tornando-se abundantes em alguns trechos ou ausentes em outros, agrupadas. Apotécios côncavos, fendendo e tornando-se retorcidos conforme envelhecem, 0,325,2 mm diâm., pedicelados, submarginais a subapicais às vezes originados de ápices subcanaliculados de lobos, margem lisa ou subcrenada raramente com lacínulas, eciliada, anfitécio liso tornando-se venado e rugoso conforme envelhece, pedicelo inflado e liso tornando-se verticalmente pregueado ou venado conforme envelhece, disco marrom, não pruinoso, imperfurado, ascósporos elipsóides, 19,0-25,0 × 9,5-12,5 $\mu \mathrm{m}$, epispório ca. 1,5$2,0 \mu \mathrm{m}$. Picnídios frequentes submarginais, abundantes nas lacínulas, de ostíolo negro. Conídios baciliformes a filiformes, arqueados, sinuosos ou torcidos em diferentes formas, 5,0-7,5 $\times c a$. 1,0 $\mu \mathrm{m}$.

Substâncias de importância taxonômica: atranorina e cloroatranorina (córtex superior), ácidos alectorônico, $\beta$-alectorônico, dehidrocolatólico, dehidroalectorônico e traços de um pigmento alaranjado $\mathrm{K}+$ vermelho escuro do tipo antraquinona (medula).

Distribuição: América do Sul. Brasil: São Paulo (Marcelli et al. 2011).

Material estudado: Brasil. São PAULO: Ilha Comprida, próximo à balsa para Cananéia, mata de restinga baixa, 03-IV-2004, A.A.Spielmann et al. 964 (holótipo, SP!).

Comentários: Parmotrema conidioarcuatum é caracterizada pela ausência de propágulos, margens densamente ciliadas e lacinuladas, formação de pequenos "buquês" de lóbulos espalhados pela submargem por todo o talo, margem inferior marrom a branca quando em lobos lacinulados ou com apotécios, apotécios de margens eciliadas, medula branca contendo manchas frequentes de pigmento alaranjado $\mathrm{K}+$ vermelho escuro, ascósporos $\leq 25,0 \mu \mathrm{m}$ compr. e conídios curto filiformes arqueados de diferentes formas.

A formação de lacínulas longas e ramificadas, os "buquês" de pequenos lóbulos e o formato variado dos conídios são as características que a separam mais facilmente de qualquer outra espécie do grupo contendo ácido alectorônico na medula. Esta espécie é também 
a que possui lobos mais largos em média (comumente ultrapassando $10 \mathrm{~mm}$ larg.) dentre todas as de mesma afinidade química.

As lacínulas tornam-se subcanaliculadas e bastante ramificadas conforme crescem, tendo o lado de baixo constantemente branco. São também frequentemente ciliadas, e às vezes de superfície mais rugosa que outros trechos do talo, aparentemente devido ao acúmulo dos picnídios sobre estas. No espécime estudado podem medir quase $2 \mathrm{~cm}$ de comprimento, amontoando-se junto aos lobos.

Os pequenos "buquês" de lóbulos que se formam submarginais por todo o talo são peculiares a esta espécie, sendo que não foram encontradas quaisquer estruturas similares dentre todos os demais espécimes estudados (o holótipo de P. subrugatum (M!) apresenta estruturas papilóides que desenvolvem lacínulas como as das margens). A princípio cogitou-se que estas aglomerações de lóbulos poderiam ser oriundas de deformações no surgimento das lacínulas, mas são tão frequentes e de formato e disposição tão regular que se tratam evidentemente de um caráter morfológico constante na espécie.

Os conídios em $P$. conidioarcuatum representam uma característica ímpar. Embora sejam curtos e aparentemente filiformes, possuem uma grande variedade de modos de arqueamento, em diferentes pontos de seu comprimento. Há conídios retilíneos, arcuados, sinuosos, subcrescentes, em formato leve de bumerangue e até "pseudo" unciformes (tendo um ápice ainda mais retorcido e espesso, evidentemente diferentes dos encontrados em P. subrugatum, P. maraense e $P$. restingense).

Parmotrema subrugatum (Krempelhuber) Hale difere pelos lobos mais estreitos, margens inferiores continuamente brancas, ascósporos maiores (26,0$39,0 \mu \mathrm{m}$ compr.) e conídios menores (4,0-6,0 $\mu \mathrm{m}$ compr.) de formato constantemente unciforme. Os espécimes analisados aqui não produzem lacínulas ramificadas e longas (são aparentemente jovens), embora haja a menção deste tipo de lacínulas em espécimes analisados em outros trabalhos (ver comentários em P. subrugatum), sendo que estas existem no holótipo (Benatti et al. 2010).

Parmotrema maraense Hale também difere pelos lobos mais estreitos, margens com lacínulas pouco ramificadas, apotécios ciliados e mais lacinulados, e em acordo com o observado por Donha (2005) também pelos conídios unciformes de mesma forma e tamanho que os encontrados em P. subrugatum.

Outra espécie relacionada, $P$. restingense, tem as margens não lacinuladas a parcialmente sublacinuladas, e também possui o mesmo tipo de conídios encontrados em P. subrugatum e P. maraense de mesmo tamanho. Os ascósporos em $P$. restingense são também maiores, medindo frequentemente entre $25,0-36,0 \mu \mathrm{m}$ compr. como ocorre também em $P$. subrugatum.

Parmotrema hyperlaciniatulum Benatti, Marcelli \& Elix. Mycotaxon 112: 378. 2010.

Figuras 3, 4

Talo lobado a sublobado, eventualmente tornando-se densamente lacinulado, cinza esverdeado a cinza pardo quando em herbário, de até $14,0 \mathrm{~cm}$ diâm., subcoriáceo a coriáceo. Lobos de ramificação irregular, 1,5-4,0 (-5,0) mm larg., de contíguos e pouco adnatos nas partes distais a pouco sobrepostos lateralmente e elevados em direção ao centro, pouco adpressos a soltos e em parte ficando pregueados e subcanaliculados conforme se transformam em lacínulas, os ápices subarredondados a irregulares e lacinulados, subplanos a subcôncavos, as margens lisas a irregulares e lacinuladas, subonduladas, subplanas a subascendentes, incisas. Superfície contínua a irregularmente quebrada, lisa a pouco rugosa, às vezes com verrucosidades papilosas. Lacínulas em geral longas, subcanaliculadas a canaliculadas, truncadas, $0,2-15,0(-30,0) \times 0,2-0,9(-1,1) \mathrm{mm}$, em início simples eventualmente tornando-se dicotômicas anisotômica ou irregularmente ramificadas, surgindo por toda a margem, porém mais abundantes no centro do talo, tornando-se emaranhadas e por vezes recobrindo o córtex superior, às vezes com verrucosidades papilosas, lado de baixo geralmente creme ou às vezes negro. Máculas fracas a distintas, lineares, laminais mais visíveis nas partes distais, às vezes originado quebras. Cílios simples a raramente furcados, $0,10-1,70(-2,40) \times c a .0,05 \mathrm{~mm}$, frequentes, distribuídos por toda a margem, inclusive nas lacínulas. Sorais, pústulas e isídios (ver lacínulas) ausentes. Medula branca, compequenasmanchasdepigmento $\mathrm{K}+$ avermelhado escuro bastante frequentes na porção inferior da medula. Lado de baixo negro, lustroso, com áreas lisas ou rugosas, pouco papiladas. Margem inferior creme ou marrom muito clara, lustrosa a opaca, 0,5-4,5 (-6,0) mm larg., nítida, creme na maior parte dos lobos que são lacinulados, a atenuada e marrom apenas nos lobos distais não lacinulados, lisa a rugosa, pouco papilada, nua. Rizinas concoloridas, simples, às vezes aglutinadas, $0,20-0,70(-1,3) \times 0,05-0,15 \mathrm{~mm}$, poucas a frequentes, agrupadas. Apotécios côncavos, 0,3-9,2 mm diâm., subpedicelados, submarginais a subapicais ou sobre as lacínulas, margem lisa tornando-se crenada ou denteado-lacinulada conforme envelhece, às vezes com alguns cílios, anfitécio e pedicelo lisos 
tornando-se rugosos e venados conforme envelhecem, disco marrom, não pruinoso, imperfurado, ascósporos elipsóides, (22,5-) 24,5-38,0 (-40,0) × 14,0-21,5 $\mu \mathrm{m}$, epispório (2,5-) 3,0-3,5 $\mu \mathrm{m}$. Picnídios submarginais, abundantes sobre as lacínulas, de ostíolo marrom a negro. Conídios unciformes curtos, 4,0-5,0 × ca. 1,0 $\mu \mathrm{m}$.

Substâncias de importância taxonômica: atranorina e cloroatranorina (córtex superior), ácidos alectorônico, $\alpha$-colatólico, $\beta$-alectorônico, $\beta$-colatólico, dehidrocolatólico, dehidroalectorônico, e traços de metil-pseudoalectoronato e metil-pseudo $\alpha$-colatolato (medula).

Material estudado: Brasil. São PAUlo: Itanhaém, Rodovia Padre Manoel da Nóbrega (SP-55) km 108, manguezal ao lado da rodovia na margem direita do rio, 10-I-1979, M.P.Marcelli \& L.R.Fontes 1669, 1670 (holótipo, SP!); idem, 01-IV-1988, M.P.Marcelli \& L.R.Fontes 2386 (SP); idem, 05-VIII-1981, M.P.Marcelli \& A.Mathey 1672 (SP); idem,21-VIII-1995, M.P.Marcelli, B.Marbach \& C.H.Ribeiro 29380 (SP).

Distribuição conhecida: América do Sul. Brasil: SP (Benatti et al. 2010).

Comentários: Parmotrema hyperlaciniatulum é caracterizada pelos lobos estreitos que formam longas lacínulas subcanaliculadas a partir dos ápices e das margens, ausência de propágulos vegetativos, apotécios denteado-lacinulados às vezes pouco cíliados, margem inferior marrom muito clara a creme, medula branca com manchas de pigmentação alaranjada $\mathrm{K}+$ avermelhada escura, ascósporos grandes e conídios unciformes pequenos.

É possível observar o surgimento, em alguns lobos e lacínulas, de pequenas verrucosidades com um aspecto papiloso, que se assemelham a isídios quando observadas a olho nu, mas que podem ser diferenciadas destes últimos em estereomicroscópio. Diferem das estruturas papilosas observadas em espécimes de $P$. subrugatum (Benatti et al. 2010) por serem bem menores, mais esparsas e ocasionais, picnidiadas e por não serem ponto de origem de lacínulas, lembrando o aspecto de um isídio grosso sem uma base constrita.

Estas estruturas papilóides não são mencionadas para $P$. subrugatum, não tendo sido encontradas estruturas similares na literatura (Vainio 1890, Lynge 1914, Hale 1965, Fleig 1997, Ribeiro 1998, Louwhoff \& Elix 1999, Eliasaro 2001, Kurokawa \& Lai 2001, Canêz 2005, Donha 2005).

Diferente de outras espécies de Parmotrema com ácidos alectorônico medular, os apotécios de $P$. hyperlaciniatulum têm pedicelos curtos e pouco inflados. Às vezes aparentam serem maiores do que na verdade são, quando surgem subapicais em lobos subcanaliculados, extendendo a partir dos ápices.

A espécie encontrada na literatura cuja descrição mais se assemelha a $P$. hyperlaciniatulum é $P$. lacinulatulum Krog, com a qual o material estudado foi identificado inicialmente. Contudo, ao comparar nosso material com a descrição de P. lacinulatulum (Krog 1991), verificou-se que esta espécie apresenta talo mais fino e frágil, lobos mais largos (5,0-8,0 mm), cílios mais longos (3,0$4,0 \mathrm{~mm})$, córtex contínuo e emaculado, medula sem pigmentação alaranjada $\mathrm{K}+\mathrm{e}$ conídios sublageniformes 7,0-7,5 $\mu \mathrm{m}$.

Embora as lacínulas descritas por Krog (1991) sejam semelhantes, não são tão longas quanto as encontradas em espécimes de $P$. hyperlaciniatulum, medindo no máximo até 9,0 mm de comprimento. É possível notar que as lacínulas de $P$. hyperlaciniatulum crescem continuamente após uma interrupção no crescimento dos lobos de onde partem, atingindo centímetros de comprimento e tornando-se de fato as ramificações que continuam o crescimento do talo. Krog (1991) mencionou também que não foram encontrados ascósporos em seu material, até hoje conhecido apenas para o leste africano.

Parmotrema subrugatum (Krempelhuber) Hale também não forma propágulos vegetativos e tem lobos lacinulados (ver comentários sobre esta espécie). As principais diferenças apresentadas para com $P$. hyperlaciniatulum consistem na formação de lacínulas menos abundantes e menores (talos desenvolvidos apresentam lacínulas em geral com menos de 1,0 cm, enquanto que talos jovens apresentam lacínulas curtas, com poucos milímetros) sendo que o crescimento dos lobos não é interrompido pelo surgimento destas lacínulas (as margens dos espécimes de P. subrugatum encontrados são mais bem definidas como sublacinuladas), margem inferior constantemente branca ou creme (a coloração marrom fica restrita a poucos lobos jovens, que logo começam a mudar de coloração) e ausência de pigmento alaranjado $\mathrm{K}+$ na medula (ver os comentários sobre $P$. subrugatum).

Parmotrema maraense Hale. Bibliotheca Lichenologica 38: 114. 1990.

Figuras 5, 6

Talo lobado a sublobado, verde acinzentado claro a pardo quando em herbário, de até $16,0 \mathrm{~cm}$ diâm., subcoriáceo, ramulícola ou corticícola. Lobos de ramificação irregular, (2,0-) 3,0-6,0 (-8,0) mm larg., de contíguos a sobrepostos lateralmente, às vezes um pouco amontoados, geralmente elevados, pouco adpressos a 

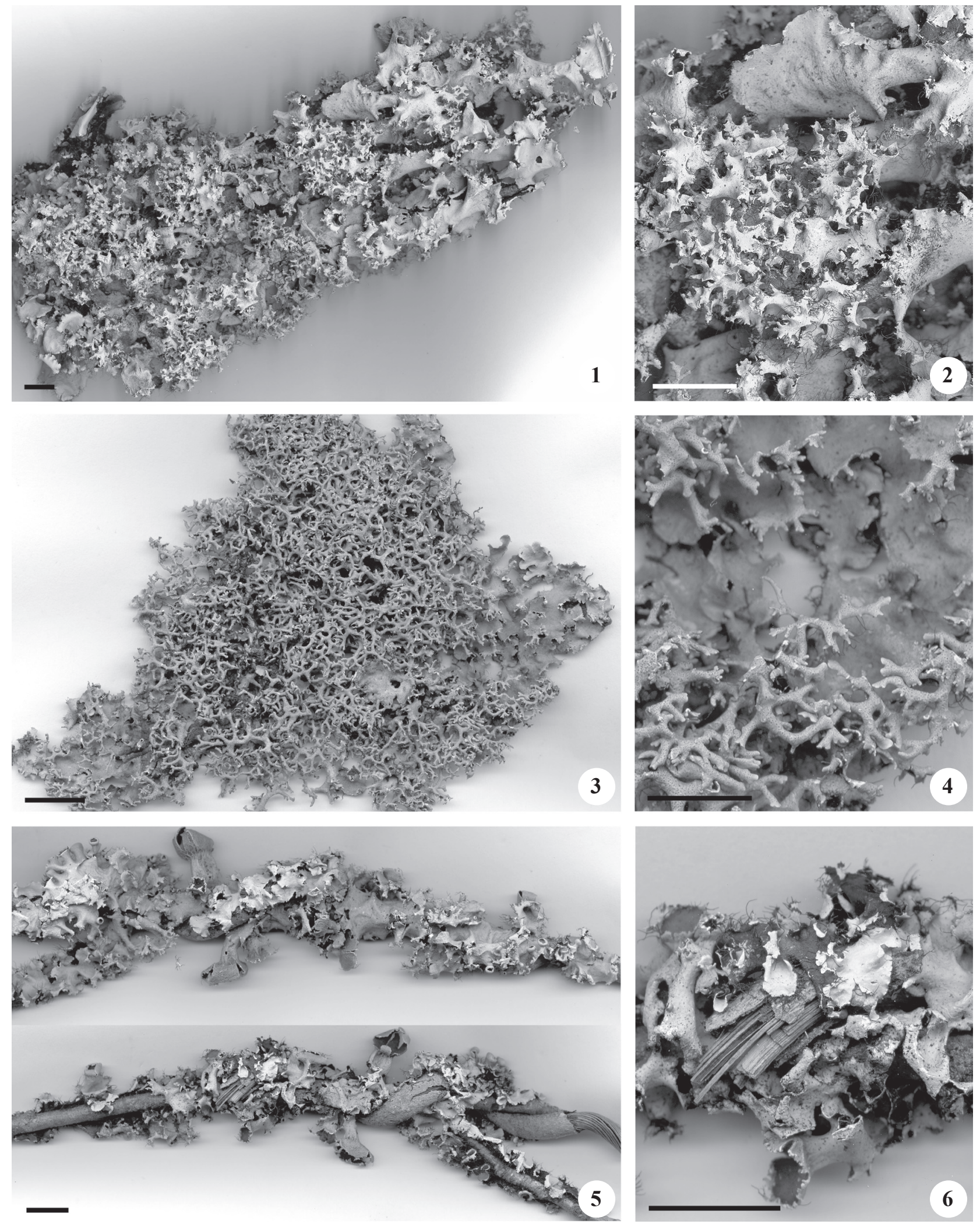

Figuras 1-2. Parmotrema conidioarcuatum. 1. Hábito. 2. Detalhe (Spielmann 964). Figuras 3-4. Parmotrema hyperlaciniatulum. 3. Hábito. 4. Detalhe (Marcelli 1670). Figuras 5-6. Parmotema maraense. 5. Hábito. 6. Detalhe (Marcelli 6640). Barra =1 cm.

Figures 1-2. Parmotrema conidioarcuatum. 1. Habit. 2. Detail (Spielmann 964). Figures 3-4. Parmotrema hyperlaciniatulum. 3. Habit. 4. Detail (Marcelli 1670). Figures 5-6. Parmotema maraense. 5. Habit. 6. Detail (Marcelli 6640). Bar $=1 \mathrm{~cm}$. 
soltos, os ápices subarredondados a irregulares, subplanos a subcôncavos, as margens lisas, subcrenadas ou irregulares, subascendentes a ascendentes, subonduladas a onduladas, em parte (sub)lacinuladas. Superfície contínua a irregularmente quebrada, lisa a pouco rugosa. Lacínulas ocasionais irregularmente distribuídas pela margem, às vezes surgindo das margens dos apotécios, curtas a medianas, subplanas a canaliculadas, truncadas, $0,3-6,0(-8,5) \times 0,2-2,0 \mathrm{~mm}$, simples ou irregulares, lado de baixo concolorido à margem inferior, branco a creme quando em lobos com apotécios. Máculas fracas quando laminais a distintas nos anfitécios e pedúnculos, puntiformes, às vezes agregadas. Cílios negros, simples às vezes furcados ou raramente irregulares, 0,2$2,2 \times c a .0,05 \mathrm{~mm}$, poucos a frequentes ou às vezes, distribuídos por toda a margem, porém ausentes ou escassos nos ápices dos lobos. Sorais, pústulas e isídios ausentes. Medula branca, sem pigmentações. Lado de baixo negro, lustroso, com áreas lisas, rugosas ou pouco venadas. Margem inferior marrom, tornando-se creme ou branca em lobos com apotécios, às vezes variegada, lustrosa, 1,0-4,0 (-6,0) mm larg., atenuadas quando marrom, nítidas quando creme ou branca, lisa a pouco venada ou pouco rugosa, nua. Rizinas concoloridas, simples a raramente furcadas ou irregulares, 0,1$0,9(-2,0) \times c a .0,05 \mathrm{~mm}$, frequentes a abundantes, homogeneamente distribuídas. Apotécios côncavos a cupuliformes, tornando-se retorcidos, fendidos, involutos ou abertos conforme envelhecem, 0,311,2 mm diâm., submarginais a subapicais, pedicelados, em parte originados de ápices subcanaliculados de lobos, margem lisa, tornando-se denticulada a lacinulada e eventualmente ciliada, anfitécio liso, tornando-se venado ou rugoso papilado conforme envelhece, pedicelo liso, inflado e dilatado, tornando-se verticalmente pregueado ou venado conforme envelhece, disco marrom, côncavo a cupuliforme, não pruinoso, imperfurado a raramente perfurado, ascósporos elipsóides, 28,0-30,0 × 12,0$15,0 \mu \mathrm{m}$, epispório (2,0-) 2,5-3,5 $\mu \mathrm{m}$. Picnídios frequentes, submarginais, abundantes nas lacínulas, de ostíolo negro. Conídios unciformes, (3,0-) 4,0-6,0 $\times c a .1,0 \mu \mathrm{m}$.

Substâncias de importância taxonômica: atranorina (córtex superior), ácidos alectorônico e $\alpha$-colatólico, traços de uma substância desconhecida (medula). Embora Hale (1990) mencione a presença do pigmento esquirina, este não foi encontrado no espécime analisado aqui.

Material estudado: Brasil. SÃo PAULO: Iguape, Barra do Ribeira, entre o "Rio" Suamirim e o oceano, mata de restinga baixa em solo alagado, 17-VII-1989, M.P.Marcelli \& O.Yano 6640 (SP).
Distribuição: América do Sul. Brasil: SP e PR (Hale 1990, Benatti 2005, Donha 2005).

Comentários: O espécime aqui nomeado Parmotrema maraense caracteriza-se pelas margens ciliadas e irregularmente lacinuladas, apotécios de margens denteado-lacinulados geralmente ciliadas quando amadurecidos, margens inferiores marrons tornando-se creme ou brancas em lobos com apotécios, ascósporos grandes para o padrão do gênero ( $c a .30 \mu \mathrm{m})$ e conídios unciformes.

Assim como ocorre na maioria das espécies contendo ácido alectorônico na medula, à exceção de Parmotrema subrugatum (Krempelhuber) Hale que tem as margens constantemente brancas, as margens do córtex inferior de $P$. maraense tornam-se de cor clara apenas em lobos contendo apotécios ou às vezes em lobos muito lacinulados.

Hale (1990) mencionou margens curto lobuladolacinuladas para $P$. maraense. O espécime analisado aqui produz lacínulas com alguns milímetros de comprimento, às vezes com quase $1,0 \mathrm{~cm}$, semelhantes às mencionadas por Donha (2005) para espécimes do Estado do Paraná. Lóbulos são muito escassos nas margens do espécime estudado, surgindo raramente em algumas partes velhas do talo.

Embora a presença de cílios seja perceptível na maior parte dos apotécios, os mais jovens costumam ter as margens eciliadas ou pouco ciliadas. Os cílios costumam aparecer com mais frequência nos apotécios de margens mais denticulado-lacinuladas (os mais amadurecidos), surgindo muitas vezes nos ápices das lacínulas.

Curiosamente, o espécime descrito tem ascósporos com o mesmo tamanho mencionado por Hale (1990) na descrição original $(28,0-30,0 \times 12,0-15,0 \mu \mathrm{m})$. De todas as espécies encontradas, $P$. maraense é a que tem a menor variação no comprimento dos ascosporos, que são em média menores que os encontrados em espécimes de $P$. subrugatum e $P$. restingense (em média 26,040,0 $\mu \mathrm{m}$ compr., com epispórios ainda mais espessos, de até $4,0 \mu \mathrm{m})$ e maiores que os encontrados em $P$. wainioi (A. L. Smith) Hale e $P$ conidioarcuatum (estes $\leq 25,0 \mu \mathrm{m}$ compr.).

Contudo, Donha (2005) mencionou ascósporos maiores para seu material de $P$. maraense, similares aos encontrados aqui nos espécimes de $P$. subrugatum e $P$. restingense, medindo $(22,0-) 25,0-37,5(-40,0) \times 12,5-$ $20,0(-22,5) \mu \mathrm{m}$.

Os conídios têm o mesmo tamanho mencionado por Hale (1990), embora na descrição original o autor tenha comentado apenas que são cilíndricos (não disse 
se baciliformes, unciformes ou outra forma). Os conídios vistos são unciformes, o que também foi visto por Donha (2005) em seu material.

Espécimes de P. subrugatum diferem pela formação de lacínulas que quando desenvolvidas, apresentam forma e padrão de distribuição regular além de serem ramificadas (ver comentários em P. subrugatum), margens inferiores constantemente brancas e, conforme explicado, ascósporos em média maiores. O próprio Hale (1990) utilizou a coloração das margens como característica para separar $P$. maraense de $P$. subrugatum em seus comentários, sem mencionar diferenças quanto aos conídios.

Parmotrema restingense difere pelas margens não lacinuladas ou sublacinuladas, devido ao recorte irregular, as lacínulas curtas (dificilmente ultrapassando 1,5 mm) e esparsas, ascósporos maiores de tamanho semelhante ao encontrado em $P$. subrugatum e pelos apotécios que em $P$. restingense são ainda sempre eciliados, mesmo os mais amadurecidos.

Parmotrema wainioi tem cílios marginais mais longos (frequentemente com até $4,0 \mathrm{~mm}$ ou mais de comprimento), apotécios também eciliados como em $P$. restingense e pouco lacinulados, raramente formando pequenos lóbulos, com ascósporos menores (16,025,0 $\mu \mathrm{m}$ compr.) que os de $P$. maraense, e os conídios são curto filiformes, medindo 5,0-7,5 (-9,0) $\mu \mathrm{m}$ compr.

Parmotrema mellissii (Dodge) Hale, Phytologia 28(4): 337. 1974. $\equiv$ Parmelia mellissii Dodge, Annals of the Missouri Botanical Garden 46: 134. 1959.

Figuras 7-12

Talo lobado a sublobado, cinza esverdeado a verde acinzentado claro tornando-se cinza pardo quando em herbário, de até $11,0 \mathrm{~cm}$ diâm., submembranáceo a subcoriáceo, ramulícola ou corticícola. Lobos de ramificação irregular, 1,0-6,0 mm larg., de contíguos a sobrepostos lateralmente tornando-se às vezes parcialmenteamontoadosnocentro, poucoadnatos a pouco elevados, pouco adpressos, os ápices subarredondados a irregulares, planos a subplanos ou subcôncavos e em parte sutilmente involutos, as margens lisas próximas aos ápices tornando-se crenadas ou irregulares em direção ao centro, subplanas a ascendentes e em parte involutas, pouco a não onduladas, normalmente incisas. Superfície contínua nas partes distais a pouco irregularmente quebrada nas partes velhas, lisa às vezes pouco rugosa ou com algumas rugas extensivas mais salientes. Lacínulas ausentes (ver descrição dos isídios). Máculas ausentes ou fracas, puntiformes, laminais ou surgindo próximas aos ápices lobos. Cílios negros, simples a raramente furcados, $0,10-3,10 \times c a .0,05 \mathrm{~mm}$, abundantes a contíguos em alguns trechos, distribuídos por toda a margem, porém menos densos a escassos nos ápices de lobos jovens, às vezes parcialmente cobertos com um pigmento cor de cobre. Sorais ausentes (ver comentários), sorédios granulares, formados pela decorticação ou desintegração dos isídios ou de pústulas. Pústulas ausentes (ver comentários). Isídios cilíndricos lisos a granulares, $0,05-0,45(-1,20) \times 0,05-0,25(-0,50) \mathrm{mm}$, simples a pouco ramificados ou eventualmente coralóides, eretos a tortuosos, firmes, concoloridos, geralmente com ápices e lados ciliados (cílios com até 3 a 5 vezes a altura dos isídios), surgindo marginais tornando-se em parte submarginais ou em menor quantidade sobre a lâmina, ápices de dobras ou rugas extensivas similares a vergões, desmanchando-se em sorédios conforme se desenvolvem ou às vezes decorticados a partir dos ápices (ver comentários). Medula branca, com escassas manchas ocasionais de pigmento alaranjado $\mathrm{K}+$ vermelho escuro surgindo na parte de baixo próximas ao córtex inferior. Lado de baixo negro, lustroso, com áreas lisas a pouco venadas ou pouco rugosas, pouco papiladas. Margem inferior marrom, tornando-se creme, branca, negra ou variegada em lobos isidiados, lustrosa, 1,0-5,0 mm larg., atenuada quando marrom a nítida quando creme ou branca, lisa a pouco venada ou pouco rugosa, nua. Rizinas concoloridas, simples a raramente furcadas ou irregulares, $0,20-2,30 \times 0,05-0,10 \mathrm{~mm}$, frequentes a abundantes, agrupadas, às vezes esparsamente (em espécimes com isídios apicalmente decorticados, são mais homogeneamente distribuídas, porém mais densamente agrupadas em certos trechos). Apotécios e picnídios não encontrados.

Substâncias de importância taxonômica: atranorina (córtex superior), ácidos alectorônico, $\alpha$-colatólico (este não encontrado no espécime pustulado), traços de um ácido graxo não identificado, e um pigmento alaranjado $\mathrm{K}+$ avermelhado escuro do tipo antraquinona/esquirina (medula). Em alguns espécimes uma parte dos cílios apresenta pigmentação cor de cobre, que reage $\mathrm{K}+$ púrpura.

Material estudado: Brasil. SÃo PAulo: Peruíbe, Rio Guaraú, mata de restinga alta e manguezal na margem esquerda do rio $c a .1 \mathrm{~km}$ da foz, 18-IV-1995, M.P.Marcelli \& C.H.Ribeiro 28475 (SP). Itanhaém, Bairro Santa Júlia, Rodovia Padre Manoel da Nóbrega km 116,5, 01-IV-1982, M.P.Marcelli \& L.R.Fontes 2422 (SP). Ilha Comprida, próximo à balsa para Cananéia, mata de restinga, 03-IV-2004, A.A.Spielmann et al. 1026 (SP); idem, parte sul da ilha próximo à balsa para Cananéia, 

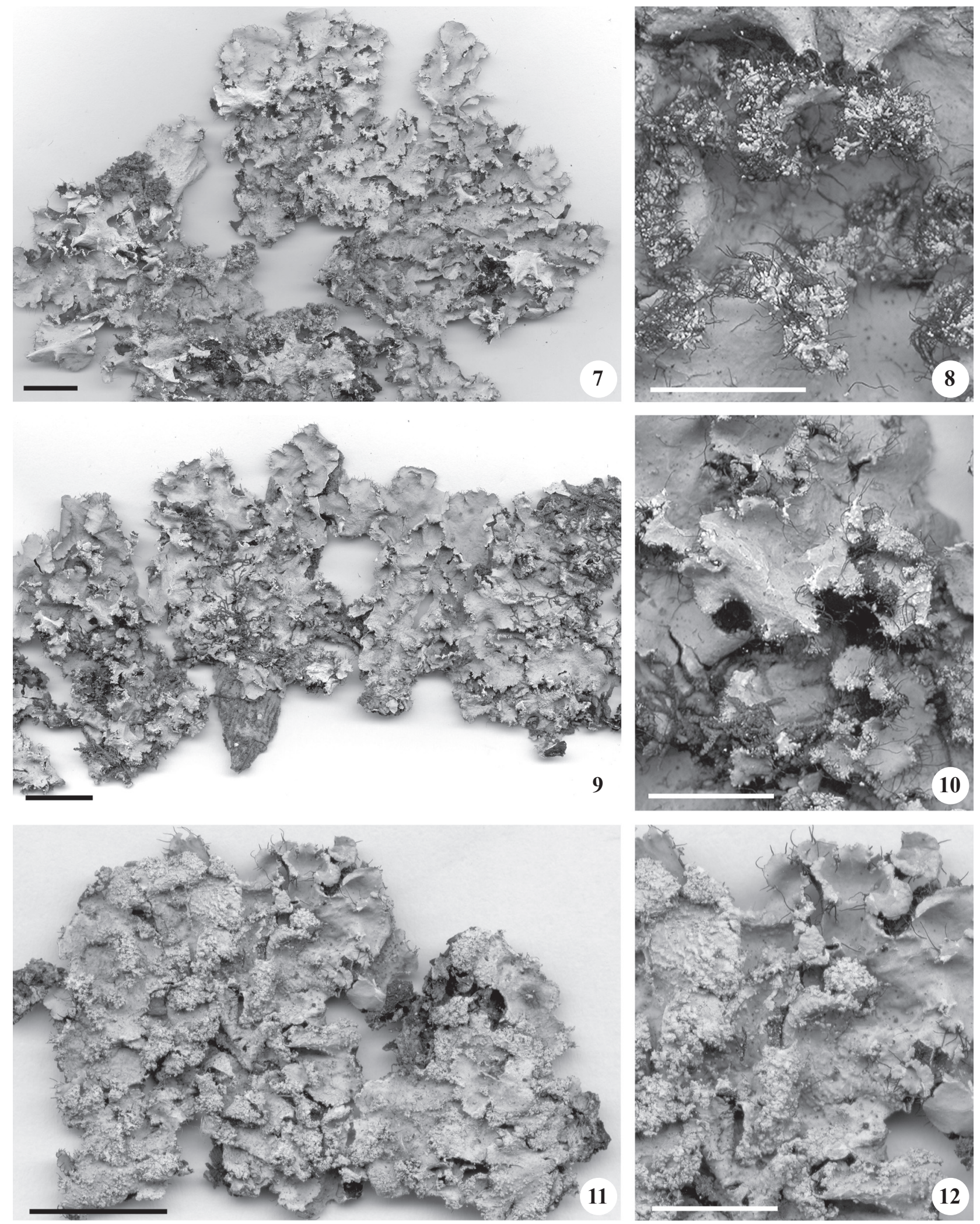

Figuras 7-12. Parmotrema mellissii. 7. Hábito. 8. Detalhe (Benatti 1800). 9. Hábito. 10. Detalhe (Marcelli 28475). 11. Hábito. 12. Detalhe (Marcelli 2422). Barra $=1 \mathrm{~cm}$.

Figures 7-12. Parmotrema mellissii. 7. Hábito. 8. Detalhe (Benatti 1800). 9. Hábito. 10. Detalhe (Marcelli 28475). 11. Hábito. 12. Detalhe (Marcelli 2422). Bar $=1 \mathrm{~cm}$. 
mata de restinga baixa, 03-IV-2004, M.N.Benatti et al. 1768,1800 (SP).

Distribuição: Oceania, Ásia, Pacífico Norte, África, Atlântico Norte, América do Norte, América Central, Caribe e América do Sul. Brasil: MG, SP, PR, SCS e RS (Hale 1959, como o sin. Parmelia allardii Hale, 1965, Krog \& Swinscow 1981, Swinscow \& Krog 1988, Pereira \& Marcelli 1989, Osório 1992, Elix 1994, Fleig 1997, Galloway \& Quilhot 1998, Sipman 2000, Eliasaro 2001, Benatti 2005, Canêz 2005 como o sin. P. allardii). Devido sinonimização de $P$. allardii em $P$. mellissii (Hale 1965) é necessária a revisão das espécies para esclarecimento. É possível que espécimes citados por diversos autores (Hale 1965, Fleig 1997, Ribeiro 1998, Eliasaro 2001) como P. mellissii tratem-se de uma espécie diferente.

Comentários: $\mathrm{O}$ nome $P$. mellissii aparentemente vem sendo utilizado para um grupo de espécies morfologicamente semelhantes contendo ácidos alectorônico e $\alpha$-colatólico medulares, mas que diferem entre si pelo formato e pela ontogenia dos propágulos vegetativos. Hale (1959) mencionou ascósporos 16,020,0 $\times$ 10,0-14,0 $\mu \mathrm{m}$ (P. allardii), citando picnídios raros e conídios não vistos. Canêz (2005) mencionou a ausência de apotécios em seu material, mas citou conídios baciliformes 6,0-7,5 $\mu \mathrm{m}$ compr.

Há diferenças encontradas nos espécimes do litoral que condizem com as visualizadas por Spielmann, Canêz e Marcelli como o comentado por Canêz (2005) e Spielmann (2005), sendo que os autores estão investigando a relação entre possíveis múltiplas espécies. Canêz (2005) comparou diversas formas encontradas na literatura (Awasthi 1976, Krog \& Swinscow 1981, Elix 1994, Fleig 1997, Ribeiro 1998, Louwhoff \& Elix 1999, Eliasaro 2001) para P. mellissii.

Segundo o conceito de Dodge (1959), antes da sinonimização de Parmelia allardii de Hale (1959) em $P$. mellissii (Hale 1965), Parmotrema mellissii apresentaria margens crenadas abundantemente ciliadas, isídios que surgem a partir das margens ou sobre rugas com aspecto de vergões que se estendem sobre partes do córtex superior e que se decompõem em sorédios granulares conforme se desenvolvem.

Entretanto foram encontrados também espécimes que se enquadram melhor à descrição original de Parmelia allardii (Hale 1959) e um espécime que deve tratar-se de uma espécie distinta porém próxima (Canêz, com. pess.), mas que atualmente só poderia ser relacionada à $P$. mellissii devido a suas características. Respectivamente, estes espécimes apresentam isídios coralóides densamente ciliados em parte decorticados, que compõe formações arbusculares de distribuição principalmente marginal, ou sorais aparentemente sem uma origem isidióide, mas pustular.

Hale (1965) havia examinado o holótipo de $P$. mellissii constatando que o espécime "apesar de pobremente desenvolvido, tem típicos isídios coralóides sorediados", além de esclarecer que a reação medular KC era positiva devido à presença do ácido alectorônico, e que não havia sinais de pigmento alaranjado $\mathrm{K}+$ na medula do espécime de Dodge, substância que também não havia sido encontrada em metade dos espécimes atribuídos à $P$. mellissii observados por ele. Hale atribui o aparecimento do pigmento (que ele acreditava tratar-se de rodoficina) à decomposição do talo, e portanto de valor taxonômico insignificante.

Isídios vistos em alguns espécimes são mais íntegros, às vezes em parte decorticados nos ápices e daí originado algo como sorédios, mas ainda mantendo o aspecto original cilíndrico, condizendo melhor com a descrição de Hale (1959) para os isídios de $P$. allardii. O espécime identificado como $P$. mellissii em acordo com a descrição de Dodge (1959) não forma estruturas arbusculares a partir de aglomerações marginais de isídios coralóides, mas isídios que se decompõe em massas de sorédios granulares logo após a fase inicial de desenvolvimento, surgindo sobre rugas com aspecto inchado que cruzam trechos do córtex superior, mencionadas por Dodge (1959), mas não por Hale (1959).

Um espécime encontrado (M.P.Marcelli \& L.R.Fontes 2422) forma sorédios granulares originados a partir da decomposição de pústulas efêmeras de origem submarginal ou subapical e que vão se espalhando pela lâmina, formando massas de sorais, estas frequentemente ciliadas, embora não tanto como os isídios. Os sorédios são frequentemente corticados, transformando-se então em grânulos que se aglomeram por superposição formando estruturas com um aspecto isidióide. Neste espécime ocorre uma reação medular $\mathrm{C}+$ amarelo atribuída a uma substância desconhecida e há presença de pigmento $\mathrm{K}+$ púrpura em parte dos cílios.

Parmotrema crinitum (Acharius) Choisy (Hale 1965, Fleig 1997 e Ribeiro 1998) é similar à P. mellissi, porém com isídios não soredióides, por apresentar ácido stíctico na medula ( $\mathrm{K}+$ amarelo e $\mathrm{P}+$ alaranjado, UV-) e pelos ascósporos maiores, variando de 23,0-30,0 $\mu \mathrm{m}$ de comprimento (Hale 1965, Fleig 1997 e Ribeiro 1998). Parmotrema internexum (Nylander) Hale ex DePriest \& B.W. Hale (Benatti 2005, Benatti \& Marcelli 2010) difere pela mesma química medular de $P$. crinitum, e apresenta isídios sempre eciliados, menores, de simples a pouco ramificados. 
Segundo Fleig (1997) e Kurokawa \& Moon (1998), Parmotrema hypomiltoides (Vainio) Kurokawa apresenta formação apenas de sorais marginais, com sorédios inicialmente mais finos e que vão tornando-se mais granulares, em parte agregados formando estruturas de aspecto isidióide (arbuscular?), e pela medula parcial a totalmente pigmentada ( $\mathrm{K}+$ avermelhado escuro) na porção inferior.

Os sorédios de $P$. hypomiltoides mencionados na descrição original de Vainio (1890) e citados por Kurokawa (Kurokawa \& Moon 1998) como tornando-se isidióides aproximam-se mais na aparência aos de $P$. mellissii (Dodge 1959) do que aos de P. allardii (Hale 1959. Fleig (1997) citou uma origem pustular para os sorédios de $P$. hypomiltoides, estes sendo eciliados.

A ontogenia da formação das estruturas em $P$. hypomiltoides é na verdade inversa à de $P$. mellissii, pois em $P$. hypomiltoides os sorédios agregam-se eventualmente em estruturas isidióides, enquanto que $P$. mellissii tem isídios que ao desenvolverem se decompõem em sorédios granulares.

Devido à necessidade de revisão deste grupo, a opção foi manter sob o nome $P$. mellissii todas as variações morfológicas condizentes com a literatura e que não pudessem ser enquadradas com nenhuma outra espécie referida: talos com isídios de ramificação variável que podem originar sorédios e/ou diretamente sorediados a partir de pústulas. Trabalhos futuros (Canêz, Spielmann \& Marcelli, com. pess.) poderão vir a esclarecer sinônimos incorretos e uma eventual terceira espécie envolvida.

Parmotrema pycnidiocarpum Benatti, Marcelli \& Elix, Mycotaxon 115: 77. 2011.

Figuras 13, 14

Talo lobado a sublobado, verde acinzentado claro a pardo quando em herbário, de até $14,5 \mathrm{~cm}$ diâm, submembranáceo, ramulícola. Lobos de ramificação irregular, 1,5-3,5(-5,0) mmlarg., sobrepostos lateralmente a amontoados, adnatos nas partes distais a elevados quando com apotécios, adpressos a pouco adpressos ou parcialmente soltos, os ápices subarredondados a irregulares, subplanos tornando-se subconvexos pela formação de apotécios, as margens lisas, subcrenadas ou irregulares, subplanas a ascendentes, subonduladas, inteiras a incisas, sublacinuladas. Superfície contínua, às vezes irregularmente quebrada em alguns trechos, lisa a pouco rugosa. Lacínulas curtas adventícias esparsas, distribuídas irregularmente pela margem misturadas a lóbulos jovens irregulares, planas,
0,3-1,3 × 0,2-1,1 mm, simples ou irregulares, agudas ou truncadas, lado de baixo concolorido à margem inferior ou creme quando em lobos com apotécios. Máculas fracas, puntiformes ou lineares, restritas à parte dos anfitécios e pedicelos dos apotécios. Cílios negros, simples a mais raramente furcados ou irregulares, $0,10-1,50 \times c a$. $0,05 \mathrm{~mm}$, frequentes, escassos apenas nos ápices dos lobos, distribuídos por toda a margem. Sorais, pústulas e isídios ausentes. Medula branca, com manchas aleatórias de pigmentação alaranjada $\mathrm{K}+$ vermelho escuro surgindo nas margens e ápices das partes velhas do talo e com frequência nos anfitécios ao redor do himênio dos apotécios. Lado de baixo negro, lustroso, com áreas lisas a pouco rugosas ou pouco venadas. Margem inferior marrom ou às vezes variegada, tornando-se creme quando em lobos com apotécios, lustrosa, 0,5-3,5 mm larg., atenuadas quando marrons a nítidas quando creme ou brancas, lisa a pouco venada, nua. Rizinas concoloridas, simples a furcadas ou irregulares, $0,10-0,80(-1,30) \times c a$. $0,05(-0,10) \mathrm{mm}$, frequentes a abundantes, em parte emaranhadas, homogeneamente distribuídas. Apotécios côncavos a urceolados 0,3-5,2 mm diâm., pedicelados, submarginais a subapicais em parte originados de ápices subcanaliculados de lobos, margem lisa a crenada, eciliada, anfitécio inicialmente liso tornando-se venado conforme envelhece, pedicelo inflado e liso tornando-se verticalmente pregueado ou venado conforme envelhece, disco marrom, não pruinoso, imperfurado, ascósporos não encontrados (himênios sem ascos). Picnídios frequentes, abundantes nos pedicelos e anfitécios dos apotécios a menos comuns submarginais, de ostíolo negro, conídios unciformes, 3,0-5,0 ×ca. 1,0 $\mu \mathrm{m}$.

Substâncias de importância taxonômica: atranorina, cloroatranorina (córtex superior), ácidos alectorônico, $\alpha$-colatólico, traços de ácidos $\beta$-alectorônico, $\beta$-collatolic, dehidrocolatólico, de metil pseudoalectoronato e metil pseudo- $\alpha$-pseudocolatolato (medula).

Distribuição: América do Sul. Brasil: SP (Benatti 2005, Marcelli et al. 2011).

Material estudado: BRASIL. São PAULO: Iguape, Barra do Ribeira, M. P. Marcelli \& O. Yano 6663 (holótipo SP!).

Comentários: Parmotrema pycnidiocarpum é caracterizada por ter lobos estreitos, margens ciliadas, ausência de propágulos vegetativos, rizinas frequentes homogeneamente distribuídas pelo córtex inferior, apotécios eciliados de base muito inflada, e picnídios dispostos principalmente sobre os anfitécios e pedicelos dos apotécios, contendo conídios unciformes curtos. 
As principais características da espécie estão relacionadas principalmente aos apotécios. Estes têm os pedicelos muito inflados, em formato de "saia rodada" mesmo desde muito jovens, fazendo com que os ápices dos lobos de onde surgem fiquem convexos, principalmente quando se formam subapicais.

A segunda característica é a presença constante de pigmento alaranjado $\mathrm{K}+$ vermelho escuro, disposto com mais frequência ao redor do himênio dos apotécios, chegando a impregnar a medula nos apotécios mais velhos. Manchas do pigmento também podem ser vistas esporadicamente nos ápices e margens dos lobos em trechos velhos do talo

Por último está a disposição incomum dos picnídios, que nesta espécie crescem quase na totalidade dos anfitécios e pedicelos dos apotécios, excetuando-se aqueles submarginais em alguns lobos, porém precisamente nos locais onde é possível observar o estágio inicial da formação de apotécios. Esta característica em particular foi a que mais chamou a atenção, uma vez que o surgimento dos picnídios parece de fato condicionado ao surgimento dos ascomas.

Apesar dos apotécios de P. subrugatum terem pedicelos inflados, nem estes ou nem quaisquer outros apotécios das demais espécies contendo ácido alectorônico medular tem o mesmo formato dos de $P$. pycnidiocarpum, nem tampouco apresentam pigmento alaranjado ao redor do himênio (esta foi a única espécie onde a pigmentação foi encontrada nesta parte do talo constantemente) ou ainda picnídios crescendo quase que exclusivamente sobre eles. As margens inferiores de P. pycnidiocarpum variam do marrom nos lobos distais ao creme quando abaixo dos apotécios, diferindo da margem constantemente branca dos lobos de P. subrugatum (ver comentários sobre esta espécie).

Parmotrema wainioi (A. L. Smith) Hale difere de P. pycnidiocarpum pelo aspecto dos apotécios e pela forma de distribuição dos picnídios, estes contendo conídios curto filiformes (5,0-7,5 $\mu \mathrm{m})$. Embora também apresente pigmentação alaranjada $\mathrm{K}+$ avermelhada em partes similares à $P$. pycnidiocarpum, a presença deste pigmento em $P$. wainioi não é aparentemente tão comum como nesta espécie, e mesmo a presença nos apotécios é reduzida a pequenas manchas ocasionais (ver comentários).

Apesar de não terem sido encontrados ascósporos no espécime de $P$. pycnidiocarpum, as espécies do grupo contendo conídios unciformes têm ascósporos normalmente maiores que as contendo conídios filiformes (respectivamente 25,0-40,0 e 15,0-25,0 $\mu \mathrm{m}$ compr.).
Parmotrema restingense Marcelli, Benatti \& Elix, Mycotaxon 112: 380. 2010.

Figuras 15, 16

Talo lobado a sublobado, cinza esverdeado claro a cinza pardo quando em herbário, de até 16,0 cm diâm., submembranáceo a subcoriáceo, ramulícola ou corticícola. Lobos de ramificação irregular, (1,5-) 2,5-6,0 (-9,0) mm larg., contíguos nas partes distais tornando-se em parte amontoados, adnatos a elevados quando com apotécios, pouco adpressos a soltos, os ápices subarredondados ou irregulares, subplanos a subconvexos e involutos, as margens lisas próximas aos ápices tornando-se subcrenadas ou irregulares em direção ao centro, subplanas a ascendentes e involutas ou então revolutas quando com apotécios, parte subonduladas, inteiras a irregularmente incisas, irregularmente sublacinuladas. Superfície contínua a irregularmente quebrada, lisa a pouco rugosa. Lacínulas adventícias irregularmente distribuídas pelas margens dos lobos, em geral poucas e esparsas, às vezes misturadas a lóbulos adventícios em partes velhas, planas, curtas, $0,3-1,4(-2,5) \times 0,2-$ $0,7 \mathrm{~mm}$, simples a irregulares, agudas a truncadas, lado de baixo concolorido à margem inferior ou creme quando em lobos com apotécios. Máculas fracas a distintas, laminais, mais frequentes nos anfitécios e pedúnculos, puntiformes, às vezes agregadas e lineares. Cílios negros, simples às vezes furcados ou raramente irregulares, $0,2-2,8 \times c a .0,05 \mathrm{~mm}$, frequentes a abundantes, distribuídos por toda a margem, porém ausentes ou escassos nos ápices de lobos jovens. Sorais, pústulas e isídios ausentes. Medula branca, raramente com manchas de pigmentação alaranjada $\mathrm{K}+$ avermelhado escuro em áreas envelhecidas. Lado de baixo negro, lustroso, com áreas lisas, a rugosas ou pouco venadas, pouco papiladas. Margem inferior marrom, tornando-se branca ou creme quando em lobos contendo apotécios, às vezes variegada, lustrosa, 1,5-5,5 (-9,0) mm larg., nítida quando marrom à atenuada quando branca ou creme, lisa a pouco rugosa, nua. Rizinas concoloridas, simples a parcialmente furcadas ou irregulares, 0,10-1,60 (-2,30) $\times c a .0,05(-0,15) \mathrm{mm}$, poucas a frequentes às vezes abundantes em alguns trechos, agrupadas, às vezes aglutinadas. Apotécios subcôncavos a cupuliformes, às vezes fendidos e retorcidos quando velhos, $0,3-$ 9,5 mm diâm., submarginais a subapicais, pedicelados, em parte originados de ápices subcanaliculados de lobos, margem lisa, tornando-se às vezes subcrenada ou lacinulada-denticulada conforme envelhece, eciliada, anfitécio liso, tornando-se venado ou rugoso conforme 
envelhece, às vezes com rugas papilosas, pedicelo inflado e liso, tornando-se verticalmente pregueado ou venado conforme envelhece, disco marrom, não pruinoso, imperfurado. ascósporos elipsóides, (19,0-) 25,0$36,0(-40,0) \times(12,0-) 14,0-18,0(-24,0) \mu \mathrm{m}$, epispório $2,5-4,0(-5,0) \mu \mathrm{m}$. Picnídios submarginais, frequentes a abundantes, de ostíolo negro, conídios unciformes, $(3,0-) 4,0-5,0(-6,0) \mu \mathrm{m} \times c a .1,0 \mu \mathrm{m}$.

Substâncias de importância taxonômica: atranorina, cloroatranorina (córtex superior), ácidos alectorônico $\alpha$-colatólico, traços de ácidos $\beta$-alectorônico e $\beta$-colatólico, e traços de metil pseudoalectoronato e de metil pseudo $\alpha$-colatolato (medula).

Material estudado: Brasil. SÃo Paulo: Cananéia, ao lado das balsas para Cananéia, manguezal ao lado da estrada, 23-XII-1979, M.P.Marcelli \& J.Vieira Filho 1593 (SP); idem, Ilha do Cardoso, restinga da Vila Marujá, vegetação de restinga pós-dunas ao sul da ilha, 20-X-1981, M.P.Marcelli 1747, 1751, 1752, $1753,1754,1755,1756,1759,1761,1762,1763$, 1764, 1766, 1767, 1768, 1769, 1770, 1771, 1772, 1775 (SP). Iguape, Barra do Ribeira, mata de restinga baixa próxima ao manguezal, 15-VII-1989, M.P.Marcelli \& O.Yano 6375 (SP); idem, mata de restinga baixa na beira do manguezal, 18-VII-1989, M.P.Marcelli \& O.Yano 6872, 6873 (SP); idem, mata de restinga pós-dunas, 19-VII-1989, M.P.Marcelli \& O.Yano 6808 (SP); idem, zona urbana, 22-VII-1989, M.P.Marcelli \& O.Yano 7112, 7117, 7134 (SP). Ilha Comprida, Gambôa Nóbrega, manguezal na margem esquerda da foz da gambôa, 16-II-1982, M.P.Marcelli 1594 (SP); idem, área central da ilha, mata de restinga baixa, 02IV-2004, M.N.Benatti et al. 1730, 1747, 1748, 1749 (SP). Itanhaém, Rodovia Padre Manoel da Nóbrega (SP-55) km 108, no cruzamento com Rio Itanhaém, manguezal ao lado da rodovia, na margem direita do rio, M.P. Marcelli \& L.R. Fontes 1669 (holótipo SP!). Peruíbe, margem do Rio Guaraú, manguezal na beira do rio, 23-VII-1988, M.P.Marcelli \& O.Yano 3907, 3909, 3927 (SP).

Distribuição: América do Sul. Brasil: SP (Benatti 2005, Benatti et al. 2010).

Comentários: Parmotrema restingense é uma espécie próxima de $P$. subrugatum (Krempelhuber) Hale. É caracterizada pelas margens bastante ciliadas, irregularmente sublacinuladas, ausência de propágulos vegetativos, apotécios de margens lisas a curto denticuladas, eciliadas, zona marginal inferior marrom exceto abaixo dos apotécios e medula branca com raras pequenas manchas de pigmento $\mathrm{K}+$ vermelho escuro em áreas velhas.
Apesar de comuns nas espécies do grupo alectorônico, espécimes de $P$. restingense muito raramente contêm manchas de pigmento alaranjado $\mathrm{K}+$ vermelho escuro. $\mathrm{O}$ pigmento está condicionado aparentemente ao envelhecimento de certos trechos do talo e foi visualizado em lobos velhos ou necrosados apenas em alguns poucos espécimes. $\mathrm{O}$ pigmento não apareceu em cromatografia.

Embora sejam similares e passíveis de serem confundidas (especialmente quando se comparam talos jovens pouco desenvolvidos), $P$. restingense tem características próprias que a separam de $P$. subrugatum mesmo quando comparada às várias descrições diferentes em literatura (ver comentários em $P$. subrugatum).

As margens inferiores em $P$. restingense são marrons, tornando-se brancas ou creme apenas quando em lobos contendo apotécios. Já em $P$. subrugatum as margens tendem a ser uniformemente brancas, adquirindo uma cor mais "suja" conforme envelhecem, diferente da distinta tonalidade creme observada em $P$. restingense. A cor marrom claro surge em P. subrugatum somente na transição da coloração das margens para o negro do centro, como um estágio intermediário muito breve.

Nos espécimes jovens de $P$. subrugatum as lacínulas apesar de curtas são às vezes até contíguas em alguns trechos, dando à margem um aspecto crenadodenticulado, surgindo com relativa frequência. Conforme os espécimes de $P$. subrugatum desenvolvem estas lacínulas de surgimento mais regular pelas margens e ápices dos lobos evoluem para um formato mais diferenciado e padronizado, sendo mais longas, bastante ramificadas e subcanaliculadas (Hale 1965, Donha 2005, Spielmann 2005, Spielmann \& Marcelli 2009, Benatti et al. 2010) que as de $P$. restingense.

Já em $P$. restingense, acontece que as margens são mais irregulares no recorte, com lacínulas mais esparsas e de formato mais irregular surgindo aleatoriamente (sublacinuladas), estando ausentes em grande parte das margens, e muitas vezes misturadas a lóbulos jovens crescendo em partes velhas. $\mathrm{O}$ aspecto sublacinulado irregular se mantém mesmo em talos bastante desenvolvidos.

Apesar de semelhantes aos de P. subrugatum e aos das demais espécies contendo ácido alectorônico medular, os apotécios de $P$. restingense têm a margem dos anfitécios variando de lisa a lacinulado-denticulada em um único talo, mesmo entre os mais amadurecidos, sendo que alguns talos podem ter mais apotécios denticulados que outros. Além desta diferença sutil, porém constante, encontrada nos espécimes de $P$. restingense, os apotécios nesta espécie são sempre eciliados. 

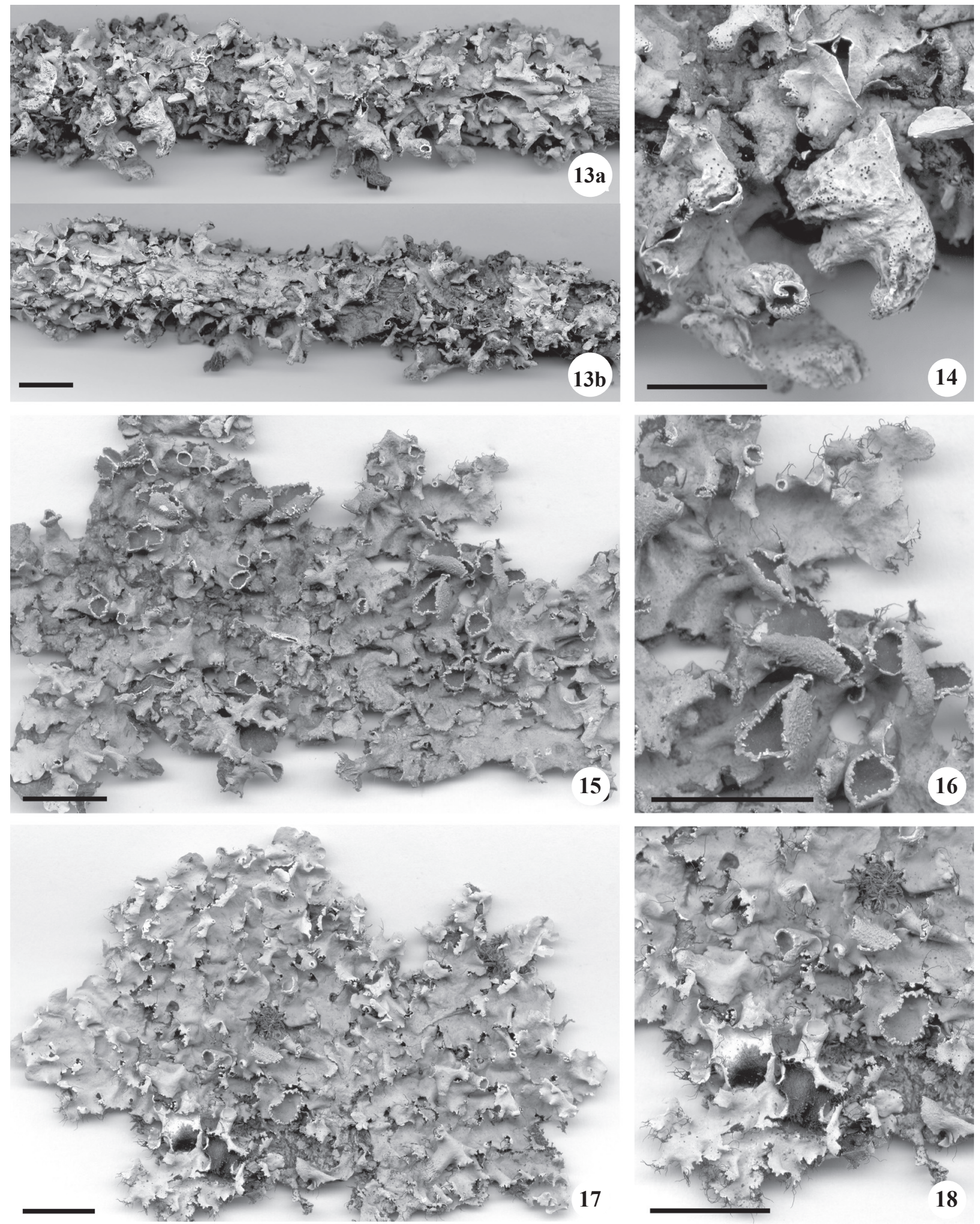

Figuras 13-14. Parmotrema pycnidiocarpum. 13a-b. Hábito. 14. Detalhe (Marcelli 6663). Figuras 15-16. Parmotrema restingense. 15. Hábito. 16. Detalhe (Marcelli 1593). 17-18. Parmotrema subrugatum. 17. Hábito. 18. Detalhe (Benatti 1785). Barra $=1 \mathrm{~cm}$.

Figures 13-14. Parmotrema pycnidiocarpum. 13a-b. Habit. 14. Detail (Marcelli 6663). Figures 15-16. Parmotrema restingense. 15. Habit. 16. Detail (Marcelli 1593). 17-18. Parmotrema subrugatum. 17. Habit. 18. Detail (Benatti 1785). Bar=1 cm. 
Parmotrema maraense Hale é também semelhante à $P$. restingense, diferindo pelas margens dos lobos e dos apotécios frequentemente lacinulados com lacínulas mais regulares e ramificadas mais longas (similares às de $P$. subrugatum) e pelos apotécios ciliados, principalmente quando amadurecidos.

Parmotrema subrugatum (Krempelhuber) Hale, Phytologia 28(4): 339. 1974. 三 Parmelia subrugata Krempelhuber. Verh. Zool. Bot. Desell. Wien 18: 320. 1868.

Figuras 17, 18

Talo lobado a sublobado, cinza esverdeado claro a cinza pardo quando em herbário, de até $8,0 \mathrm{~cm}$ diâm., submembranáceo a subcoriáceo, ramulícola ou corticícola. Lobos de ramificação irregular, 2,05,0 mm larg., contíguos a pouco imbricados, adnatos a pouco elevados, adpressos a pouco adpressos, os ápices subarredondados, subplanos, as margens lisas próximas aos ápices tornando-se subcrenadas ou crenadas em direção ao centro, subonduladas, subplanas a ascendentes e involutas, inteiras a incisas, parcialmente sublacinuladas. Superfície contínua a irregularmente quebrada, lisa a pouco rugosa. Lacínulas \pm agrupadas em alguns trechos pelas margens dos lobos, planas, curtas, 0,3$0,8(-1,3) \times 0,2-0,6 \mathrm{~mm}$, simples a raramente irregulares, truncadas, lado de baixo concolorido à margem inferior (ver comentários). Máculas fracas a distintas quando laminais a sempre distintas nos apotécios, puntiformes, às vezes agregadas e lineares. Cílios negros, simples às vezes furcados ou irregulares, 0,2-2,0 $\times c a$. 0,05 mm, frequentes, distribuídos por toda a margem, porém ausentes ou escassos nos ápices de lobos jovens. Sorais, pústulas e isídios ausentes. Medula branca, sem pigmentações (ver comentários). Lado de baixo negro, lustroso, com áreas lisas, rugosas ou venadas. Margem inferior uniformemente branca, tornando-se brevemente marrom clara antes de passar a negro no centro, branca suja quando em talos velhos ou herborizados, raramente variegada, lustrosa, 1,0-4,0 (-10,0) $\mathrm{mm}$, atenuada a quase nítida dependendo variavelmente da extensão da coloração marrom intermediária, lisa a venada ou pouco rugosa, nua. Rizinas concoloridas ou marrons, simples, furcadas ou irregulares, $0,10-1,20(-1,50) \times$ ca. $0,05(-0,15) \mathrm{mm}$, frequentes a abundantes, agrupadas, porém mais dispersas em alguns trechos próximos às margens, às vezes aglutinadas. Apotécios côncavos a cupuliformes, 0,3-5,2 mm diâm., submarginais a subapicais, pedicelados, às vezes originados dos ápices subcanaliculados de lobos, margem lisa tornando-se denticulada-lacinulada conforme envelhece, eciliada ou raramente com cílios esparsos, anfitécio liso tornando-se venado ou rugoso conforme envelhece, pedicelo inflado e liso tornando-se verticalmente pregueado ou venado conforme envelhece, disco marrom, não pruinoso, imperfurado, ascósporos elipsóides, 25,5$36,0(-39,0) \times(14,0-) 15,0-18,5(-20,0) \mu \mathrm{m}$, epispório 2,5-3,5 (-4,0) $\mu \mathrm{m}$. Picnídios submarginais, escassos a frequentes, de ostíolo negro, conídios unciformes, $(3,0-)$ 4,0-5,0 $(-6,0) \times c a .1,0 \mu \mathrm{m}$.

Substâncias de importância taxonômica: atranorina (córtex superior), ácidos alectorônico e $\alpha$-colatólico, com ou sem pigmento alaranjado $\mathrm{K}+$ vermelho escuro rodofiscina (medula).

Material estudado: BRASIL. Rio DE JANEIRO: Serra dos Órgãos, Helmreichen s.n (holótipo M!). SÃo PAUlo: Ilha Comprida, área central da ilha, mata de restinga baixa, 03-IV-2004, M.N. Benatti et al. 1785 (SP). Itanhaém, Bairro Jardim Grandesp, km 116 da Rodovia Padre Manoel da Nóbrega, mata de restinga alta, 06-VIII-1981, M.P.Marcelli \& A.Mathey 1017 (SP).

Distribuição: Oceania, Ásia, África, América do Norte, América Central, Caribe e América do Sul. Brasil: MG, RJ, SP, PR e RS (Hale 1965, Osório 1972, 1977, Ribeiro 1998, Louwhoff \& Elix 1999, Kurokawa \& Lai 2001, Benatti 2005, Canêz 2005, Spielmann 2005, Spielmann \& Marcelli 2009).

Comentários: Segundo a literatura (Vainio 1890, Lynge 1914, Hale 1965, 1979, Elix 1994, Fleig 1997, Ribeiro 1998, Louwhoff \& Elix 1999, Eliasaro 2001, Kurokawa \& Lai 2001, Canêz 2005, Donha 2005, Spielmann 2005), Parmotrema subrugatum apresentaria uma variabilidade grande de características.

As descrições na literatura citada apresentam uma grande variação com similaridades e diferenças entre si. Comparando o que os vários autores apontaram o conceito desta espécie é ainda bastante confuso e deixa dúvidas à respeito de que na verdade de mais de uma espécie está sendo chamada de $P$. subrugatum, sendo a dificuldade principal a correta circunscrição dos caracteres das mesmas. A espécie $P$. restingense é certamente uma delas.

Comparando os talos de $P$. restingense encontrados no litoral com o material tipo de $P$. subrugatum e um outro espécime adicional (Benatti et al. 2010), os caracteres que definem esta última espécie são os talos submembranáceos de margens ciliadas sublacinuladas (quando jovens) a lacinuladas (quando maduros), córtex superior e apotécios maculados, margem inferior predominantemente branca, apotécios de margens 
crenadas a denticulado-lacinuladas eciliadas a ciliadas (ao menos quando desenvolvidos), ascósporos grandes para o padrão do gênero e conídios unciformes curtos.

Para chegar ao nome P. subrugatum, tentou-se selecionar as características concordantes entre as descrições encontradas. O tamanho e o formato dos conídios foram algumas das mais conflitantes. São descritos pelos vários autores citados (à exceção de Hale 1965 e Kurokawa \& Lai 2001) atingindo desde 5,0 a até $9,0 \mu \mathrm{m}$ comprimento, variando de baciliformes a sublageniformes ou unciformes (ver tabela 1), sendo que $P$. subrugatum era até poucos anos atrás a única espécie do gênero para a qual era mencionado este último tipo de conídio (tendo recentemente sido descritas $P$. hyperlaciniatulum, $P$. restingense e $P$. pycnidiocarpum).

Estranhamente, Hale (1965) mencionou que conídios não foram vistos, embora tenha afirmado ao reestudar o material de Lynge (Hale 1960), que eram realmente um tanto arqueados como o autor descrevera (Lynge 1914). Lynge havia inclusive descrito Parmelia subrugata var. arcuata a partir dos conídios curtos e arqueados que havia encontrado em seus espécimes, uma vez que não havia menção de conídos para o material tipo de P. subrugatum, e também pela aparente diferença notada por ele na altura do himênio.

Fleig (1997) mencionou conídios unciformes na descrição da espécie e sublageniformes na chave, com tamanhos maiores que os citados pela maioria dos demais autores relacionados anteriormente (5,0-9,0 $\mu \mathrm{m}$ compr.). Eliasaro (2001) mencionou conídios do mesmo tamanho que os de Fleig, porém "cilíndricos a sublageniformes, retos ou levemente curvados".

Conídios baciliformes 4,0-5,0 $\mu \mathrm{m}$ compr. foram citados por Vainio (1890), Elix (1994) e Louwhoff \& Elix (1999). Eliasaro (2001) mencionou conídios medindo 5,0-8,0 $\mu \mathrm{m}$, compr. e Donha (2005) medindo 5,0-7,0 $\mu \mathrm{m}$ compr., baciliformes a unciformes, sendo que Donha atribuiu a diferença na forma à uma aparente variação intraespecífica, pela proximidade nas demais características de seus espécimes. Conídios unciformes foram mencionados ainda por Spielmann (2005) e Canêz (2005), com tamanhos similares aos vistos aqui.

Pelo pequeno tamanho e ápice sutilmente afinado e arqueado, é possível que o formato unciforme dos conídios tenha passado desapercebido pelos autores que o tenham mencionado como baciliformes. Caso contrário, se o formato for um diferencial apesar do tamanho idêntico, há então mais uma evidência de que há possívelmente mais uma espécie sendo chamada de P. subrugatum.
Há pequenas variações nos tamanhos dos ascósporos mencionados pelos diferentes autores na literatura, sendo que 26,0-34,0 $\mu \mathrm{m}$ compr. é a média mais comum (e.g. Vainio 1890, Lynge 1914, Hale 1965, Elix 1994, Eliasaro 2001, Spielmann 2005). Sipman (2004) e Hale (1965) separaram P. argentinum (Krempelhuber) Hale de $P$. subrugatum apenas pelos ascósporos, que medem $c a$. 11,0-22,0 $\mu \mathrm{m}$ compr. e pelo himênio que tem a metade da altura. Apenas Louwhoff \& Elix (1999) e Eliasaro (2001) mencionaram ascósporos em média 23,030,0 $\mu \mathrm{m}$ comprimento em espécimes de $P$. subrugatum, mas ainda assim maiores que os mencionados para $P$. argentinum.

A presença ou ausência de cílios nos apotécios de P. subrugatum são outra divergência. Fleig (1997), Ribeiro (1998), Canêz (2005) e Spielmann (2005) citaram apotécios eciliados, Hale (1965), Elix (1994), Louwhoff \& Elix (1999) e Donha (2005) mencionaram apotécios ciliados, enquanto Vainio (1890) e Eliasaro (2001) citaram apotécios parcialmente ciliados.

Conforme averiguado nos espécimes estudados, incluso o material tipo de $P$. subrugatum, estes têm apotécios parte eciliados e parte ciliados, este últimos com cílios escassos e curtos. Como também citadas em todas as descrições encontradas, as margens dos apotécios também são crenadas e denticuladas com pequenas lacínulas. O que ocorre é que o surgimento de cílios é aparentemente condicionado ao estágio de desenvolvimento dos apotécios e apenas sobre as pequenas lacínulas na margem do anfitécio (o mesmo foi visto ocorrer em espécimes de $P$. wainioi). Portanto, a partir de um determinado estágio de maturação, os talos podem variar desde só com apotécios eciliados a quase todos ciliados.

Assim como o surgimento de cílios nos apotécios, a presença de lacínulas marginais, seu formato e comprimento estão condicionados ao estágio de maturação dos talos. Nenhum do dois espécimes do litoral possui lacínulas longas, pois são talos jovens, sendo ambos sublacinulados (no material tipo medem 1,2-8,3 × 0,3-1,2 mm, são planas a subcanaliculadas de ápices truncados, comumente ciliadas e de lado de baixo concolorido a margem inferior, e tornam-se dicotômicas irregulares frequentemente aglomeradas). As lacínulas e o aspecto das margens mencionados nas descrições de Eliasaro (2001), Louwhoff \& Elix (1999), Kurokawa \& Lai (2001) e Canêz (2005), aparentemente ausentes ou muito curtas, são as mais parecidas com as vistas no material do litoral, dificilmente ultrapassando $1,5 \mathrm{~mm}$.

Fleig (1997) por sua vez, mencionou lacínulas mais curtas (1,0-2,0, às vezes até $5,0 \mathrm{~mm})$, mas com o mesmo 
Revista Brasil. Bot., V.34, n.3, p.261-283, jul.-set. 2011

\begin{tabular}{|c|c|c|c|c|c|c|c|c|c|c|}
\hline 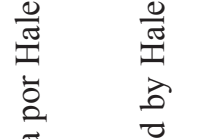 & 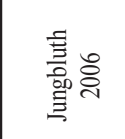 & 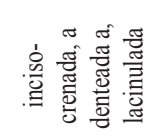 & 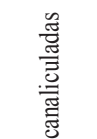 & $?$ & 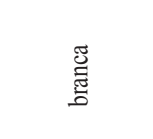 & 宽 & 总 & 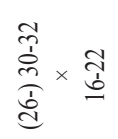 & 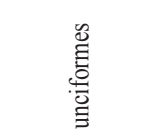 & $\begin{array}{l}0 \\
\stackrel{1}{1} \\
x \\
0 \\
i \\
i n\end{array}$ \\
\hline 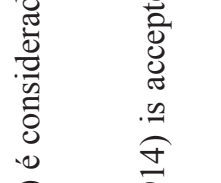 & 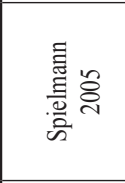 & 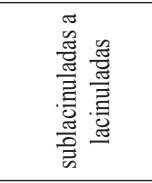 & 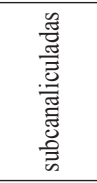 & 苑 & 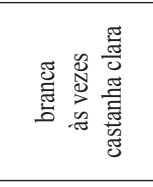 & 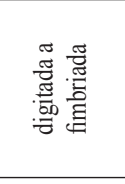 & : & 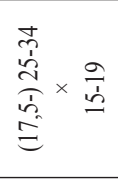 & 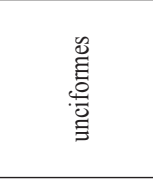 & $\begin{array}{l}0 \\
\dot{1} \\
x \\
n \\
n \\
0 \\
0 \\
i\end{array}$ \\
\hline 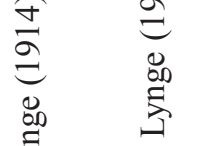 & 密 & 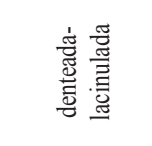 & 1 & 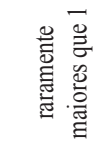 & 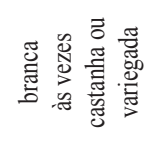 & 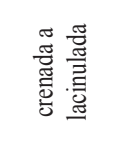 & : & 总 & 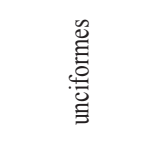 & $\begin{array}{l}\frac{1}{x} \\
x \\
\frac{d}{2}\end{array}$ \\
\hline 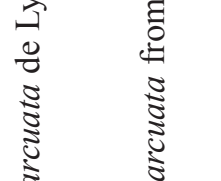 & 丞 气े & 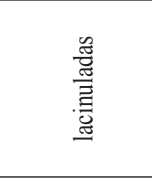 & 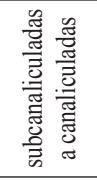 & 1 & 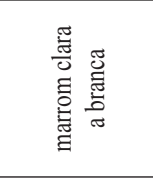 & 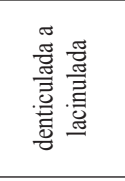 & 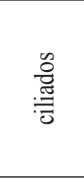 & 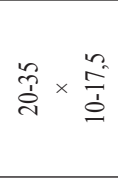 & 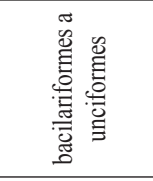 & $\begin{array}{l}\vec{x} \\
\text { in } \\
\text { in }\end{array}$ \\
\hline 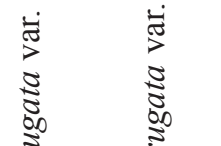 & 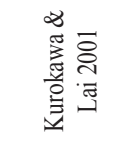 & 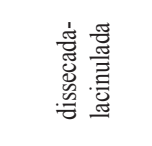 & 1 & 1 & 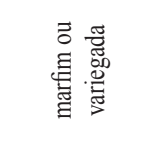 & 1 & 1 & & 1 & 1 \\
\hline 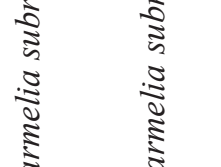 & $\begin{array}{l}\text { 总 } \\
\text { 兽 }\end{array}$ & 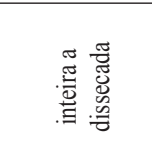 & I & 1 & 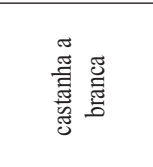 & 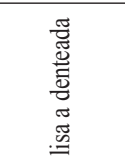 & 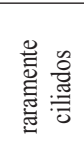 & 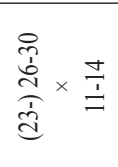 & 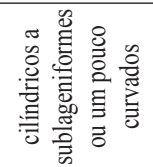 & $\begin{array}{l}\vec{x} \\
o \\
i n \\
i n\end{array}$ \\
\hline 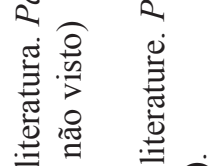 & 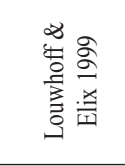 & 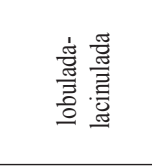 & 1 & 1 & 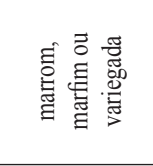 & 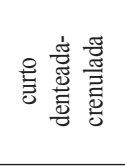 & 总 & 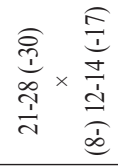 & 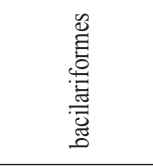 & 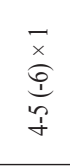 \\
\hline 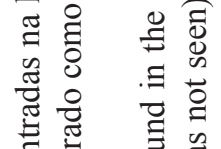 & 용 & $\begin{array}{l}\text { 芯 } \\
\text { 言 } \\
\text { 言 }\end{array}$ & 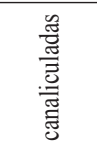 & 1 & 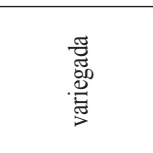 & 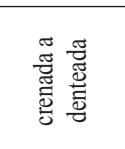 & : & 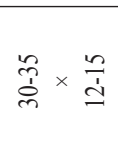 & 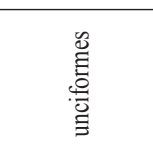 & $\begin{array}{l}2 \\
2 \\
x \\
+7 \\
+7\end{array}$ \\
\hline 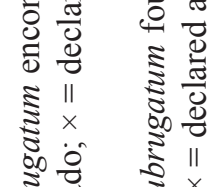 & 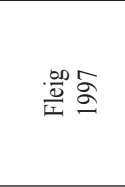 & 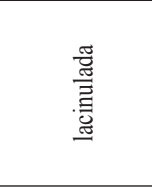 & 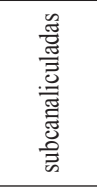 & 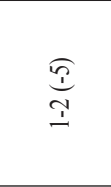 & 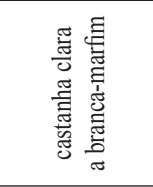 & 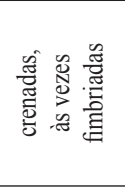 & 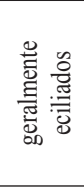 & 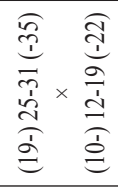 & 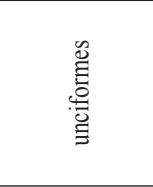 & 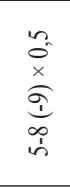 \\
\hline 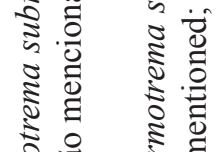 & $\not f$ & 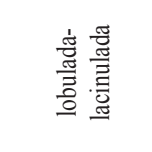 & 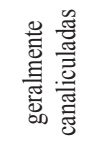 & 1 & 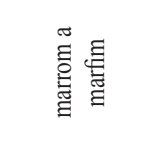 & 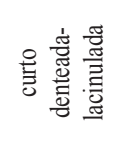 & 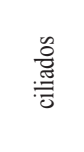 & 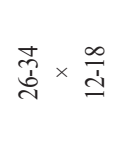 & 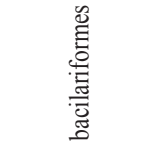 & $\begin{array}{l}\vec{x} \\
\stackrel{y}{y}\end{array}$ \\
\hline $\begin{array}{ll}2 & \overrightarrow{0} \\
4 & = \\
0 & \| 1 \\
0 & 1\end{array}$ & $\because 3$ & 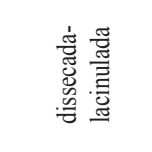 & 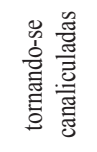 & 1 & 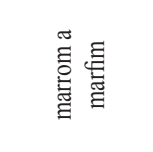 & 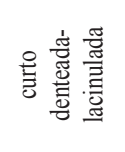 & 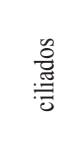 & 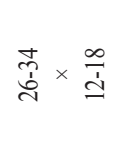 & $\times$ & $\times$ \\
\hline 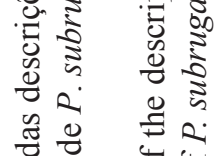 & 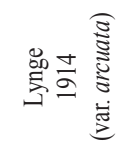 & 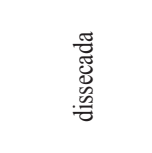 & 1 & 1 & 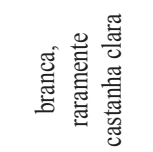 & 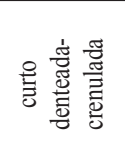 & 兽 & 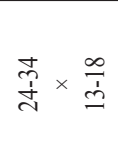 & 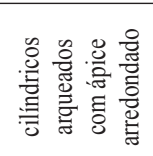 & $\begin{array}{l}n \\
2 \\
x \\
i \\
y\end{array}$ \\
\hline 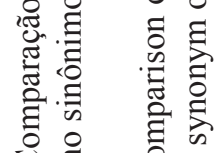 & 을 용 & 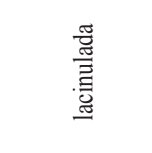 & 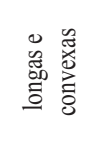 & \begin{tabular}{l}
$\pi$ \\
\multirow{2}{\pm}{} \\
0
\end{tabular} & 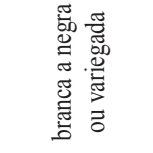 & 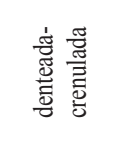 & 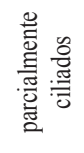 & $\stackrel{+}{\stackrel{d}{d}} \times \frac{\infty}{\grave{b}}$ & 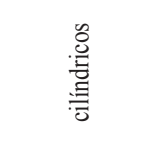 & $\begin{array}{l}\vec{x} \\
\dot{y} \\
\dot{y}\end{array}$ \\
\hline 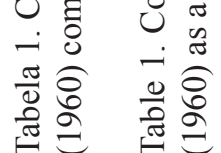 & 这 & 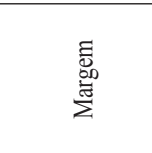 & 总 & 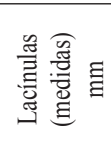 & 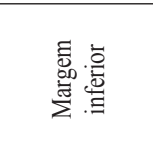 & 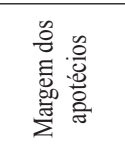 & 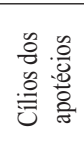 & 总高 & 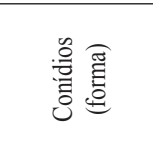 & 总 \\
\hline
\end{tabular}


formato subcanaliculado mencionado pelos autores que descrevem lacínulas longas para seus respectivos espécimes. Ocorre que conforme visto no material tipo e em outro espécime estudado (A.A. Spielmann 360 ), as lacínulas tendem a desenvolver conforme os talos atingem determinados estágios de crescimento (Benatti et al.2010), e ficar tal como descritas por Vainio (1890), Hale (1965), Ribeiro (1998), Donha (2005) e Spielmann (2005), que mecionaram lacínulas marginais em parte subcanaliculadas com vários milímetros de comprimento.

A coloração branca na margem no córtex inferior é uma característica consistente descrita por todos os autores, ainda que a coloração varie de parcial a total, dependendo da descrição. Enquanto a maioria descreveu a margem inferior variando de marrom a branca ou variegada (Hale 1965, Elix 1994, Fleig 1997, Louwhoff \& Elix 1999, Eliasaro 2001, Canêz 2005, Donha 2005), alguns mencionaram como branca a negra (Vainio 1890, Kurokawa \& Lai 2001).

As descrições da margem inferior feitas por Spielmann (2005) e Spielmann \& Marcelli (2009) são as que mais se identificam com o material do litoral e também com o tipo, onde as margens são integralmente brancas, passando a marrom claro conforme seguem em direção ao centro e posteriormente enegrecendo. Há dúvidas se as margens marrons referidas pelos demais autores relacionados são marrons parcialmente brancas como em outras espécies de Parmotrema ou se na verdade são como as descritas por Spielmann (2005) e aqui neste trabalho. O espécime de Spielmann (A.A. Spielmann 360) foi o estudado junto ao material tipo de P. subrugatum (Benatti et al. 2010).

Embora alguns autores mencionem a ocorrência de pigmentação alaranjada $\mathrm{K}+$ na medula de espécimes de P. subrugatum (Hale 1965, Elix 1994, Fleig 1997, Louwhoff \& Elix 1999, Kurokawa \& Lai 2001), a presença de pigmentação não foi detectada em nenhum dos espécimes estudados, assim como não foi detectada no material tipo, mesmo nas partes velhas do talo. A ausência de pigmentos é mencionada também por outros autores brasileiros (Ribeiro 1998, Eliasaro 2001, Canêz 2005, Donha 2005, Spielmann 2005), à exceção apenas de Fleig (1997).

Em concordância com Hale (1990) e Sipman (2004), P. maraense Hale pode ser diferenciada de P. subrugatum praticamente apenas pela coloração da margem inferior, constantemente marrom (se torna branca apenas abaixo de apotécios), e pela ausência de máculas corticais, tal como Hale (1990) afirmou em seus comentários de $P$. maraense ao diferenciar as duas espécies.
Segundo a descrição de $P$. maraense feita por Hale (1990) os conídios são cilíndricos medindo 5,0$6,0 \mu \mathrm{m}$ compr., e os ascósporos descritos medem 28,0 $30,0 \mu \mathrm{m}$, o que torna difícil certificar as diferenças entre estas espécies (ver comentários em $P$. maraense). Hale mencionou que a margem dos apotécios é ciliada, mas não evidenciou a frequência do surgimento de cílios como em $P$. subrugatum.

A presença do pigmento alaranjado $\mathrm{K}+$ esquirina é citada por Hale (1990) e Sipman (2004) para $P$. maraense, sendo que segundo o primeiro autor, o pigmento apareceria em grande quantidade na porção inferior a medula. Não foi encontrada pigmentação no espécime do litoral.

$\mathrm{O}$ pigmento alaranjado $\mathrm{K}+$ é mencionado como rodoficina por Hale (1965), enquanto outros autores mencionam o pigmento como esquirina. Ribeiro (1998), Eliasaro (2001), Donha (2005), Canêz (2005) e Spielmann (2005), não mencionaram qualquer pigmentação na medula em seus espécimes.

Parmotrema wainioi (A. L. Smith) Hale é diferenciada pela ausência de lacínulas marginais, margem inferior de coloração clara somente nos lobos contendo apotécios, margem dos apotécios eciliada, ascósporos menores ( $c a$. 16,0-25,0 $\mu \mathrm{m}$ compr.) e pelos conídios um pouco mais longos e de formato filiforme $(5,0-8,0 \mu \mathrm{m})$.

Na tabela 1 são apresentados os dados relativos às principais características mencionadas para $P$. subrugatum na literatura, e que compreendem o foco das dúvidas sobre as divergências entre as descrições de diferentes autores para a espécie.

Parmotrema wainioi (A. L. Smith) Hale, Phytologia 28(4): 339. 1974. 三 Parmelia wainii A. L. Smith, Journal of the Linnean Society of London 46: 85. 1922.

Figuras 19, 20

Talo lobado a sublobado, cinza esverdeado claro a cinza pardo quando em herbário, de até $20,0 \mathrm{~cm}$ diâm., membranáceo a subcoriáceo, ramulícola ou corticícola. Lobos de ramificação irregular, 3,5-11,0 mm larg., sobrepostos lateralmente a amontoados ou raramente contíguos, pouco adnatos a pouco elevados, pouco adpressos tornando-se soltos quando com apotécios, os ápices subarredondados, subplanos a subcôncavos, às vezes revolutos ou involutos, as margens lisas próximas aos ápices tornando-se crenadas a irregulares em direção ao centro, subplanas a subascendentes, mais ascendentes quando com apotécios, às vezes involutas ou revolutas, não onduladas a subonduladas, inteiras 

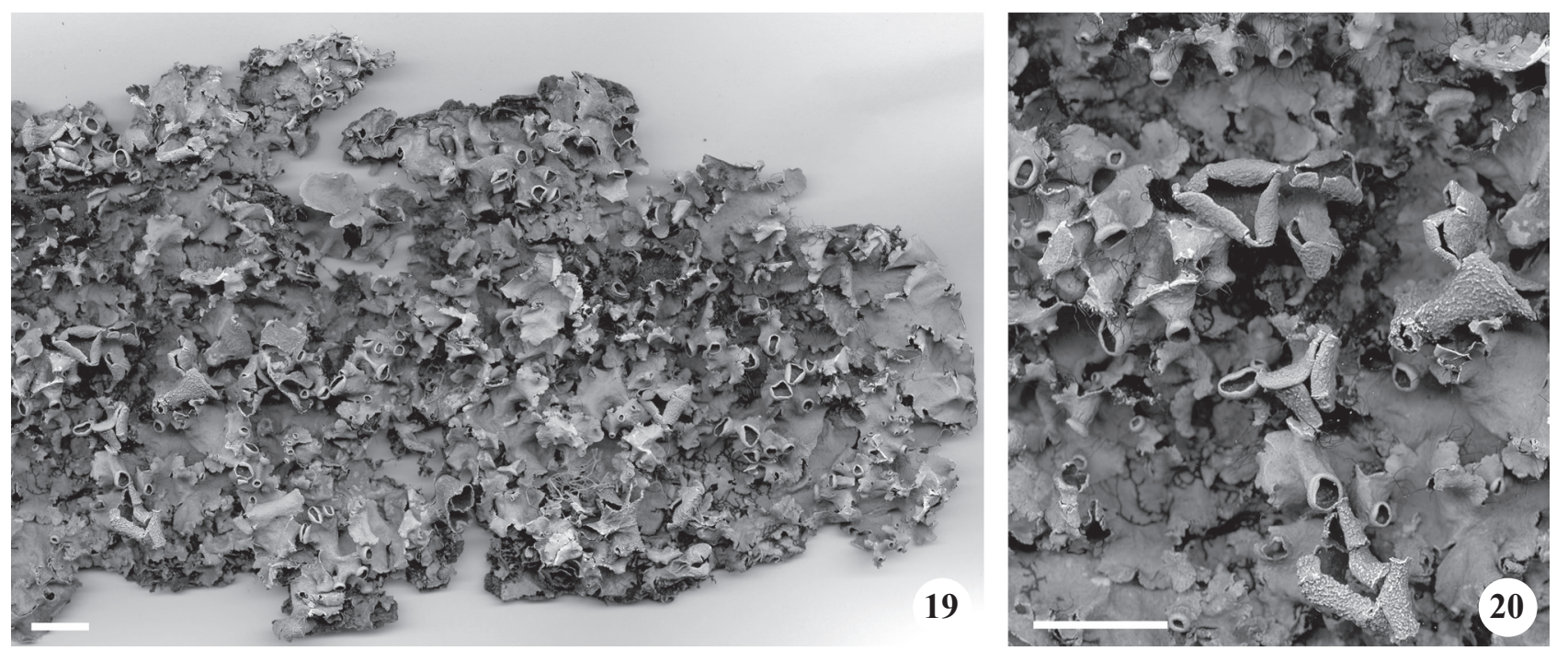

Figuras 19-20. Parmotrema wainioi. 19. Hábito. 20. Detalhe (Marcelli 6550). Barra $=1 \mathrm{~cm}$.

Figures 19-20. Parmotrema wainioi. 19. Habit. 20. Detail (Marcelli 6550). Bar $=1 \mathrm{~cm}$.

a pouco incisas, pouco sublacinuladas. Superfície contínua a irregularmente quebrada, lisa a pouco rugosa. Lacínulas ausentes a escassas e irregularmente distribuídas pelas margens dos lobos, ocasionalmente um pouco mais frequentes no centro, às vezes misturadas à lóbulos jovens irregulares adventícios, curtas às vezes um pouco alongadas, planas a subcanaliculadas, 0,3$1,2(-3,8) \times 0,2-0,8(-1,4) \mathrm{mm}$, simples ou irregulares, agudas ou truncadas, lado de baixo concolorido à margem inferior ou creme quando em lobos com apotécios. Máculas puntiformes a lineares, fracas a distintas quando laminais, sempre distintas nos anfitécios e pedicelos. Cílios negros, simples ou furcados, $0,20-$ $4,10(-6,30) \times c a .0,05(-0,10) \mathrm{mm}$, abundantes por toda a margem, porém escassos nos ápices de lobos jovens. Sorais, pústulas e isídios ausentes. Medula branca, com manchas aleatórias de pigmento $\mathrm{K}+$ vermelho escuro ausentes ou presentes, em lobos com apotécios logo abaixo do himênio ou espalhadas na porção inferior. Lado de baixo negro, lustroso, com áreas lisas a pouco rugosas ou às vezes pouco venadas, pouco papiladas. Margem inferior marrom, tornando-se creme em lobos com apotécios, às vezes variegada, opaca a lustrosa, 1,0-4,0 (-7,0) mm larg., atenuada quando marrom a nítida quando creme, lisa a pouco rugosas ou pouco venada, nua. Rizinas concoloridas, simples às vezes furcadas ou irregulares, $0,10-3,10 \times 0,05-0,10 \mathrm{~mm}$, frequentes, variando para escassas ou abundantes em alguns trechos, homogeneamente distribuídas. Apotécios côncavos a cupuliformes, fendendo e se tornando retorcidos, involutos ou abrindo conforme envelhecem,
0,3-13,4 mm diâm., laminais a submarginais ou subapicais, pedicelados, às vezes originados de ápices subcanaliculados de lobos, margem lisa ou pouco crenada, raramente com pequenos lóbulos, eciliados (ver comentários), anfitécio liso tornando-se venado conforme envelhece, pedicelo inflado e liso, tornando-se verticalmente pregueado ou venado conforme envelhece, disco marrom, não pruinoso, imperfurado, ascósporos elipsóides, $16,0-25,0 \times 10,0-15,0 \mu \mathrm{m}$, epispório 1,0$1,5(-2,0) \mu \mathrm{m}$. Picnídios submarginais, frequentes, de ostíolo negro ou raramente marrom, conídios filiformes curtos, 5,0-7,5 (raramente -9,0) × ca. 1,0 $\mu \mathrm{m}$.

Substâncias de importância taxonômica: atranorina (córtex superior), ácido alectorônico, pigmento alaranjado $\mathrm{K}+$ vermelho escuro detectado em parte do material estudado (medula). Uma substância medular que poderia se tratar de ácido glomélico(?) foi detectada em cromatografia.

Material estudado: BRASIL. MinAs Gerais: Caraça, Vainio Lichenes Brasiliensis Exsiccati 400 (holótipo TUR-V!). São PaUlo: Iguape, Barra do Ribeira, mata de restinga na beira de manguezal, 17-VII-1989, M.P.Marcelli \& O.Yano 6550, 6558, 6653 (SP); idem, 18-VII-1989, M.P.Marcelli \& O.Yano 6871 (p.min. p.) (SP). Ilha Comprida, parte central da ilha, mata de restinga, 02-IV-2004, A.A.Spielmann, et al. 829 (SP); idem, parte sul da ilha, próximo à balsa para Cananéia, mata de restinga baixa, 03-IV-2004, L.S.Canêz et al. 1237(SP); idem, 02-IV-2004, L.S.Canêz et al. 1305 (SP); idem, 03-IV-2004, M.N.Benatti et al. 1772, 1780 (SP). 
Distribuição: Oceania, África e América do Sul. Brasil: GO, MG, RJ, SP, PR, SC e RS (Vainio 1890, Hale 1965, Fleig 1997, Ribeiro 1998, Eliasaro 2001, Marcelli 2004, Benatti 2005, Donha 2005, Feuerer 2005, Spielmann 2005, Jungbluth 2006).

Comentários: Parmotrema wainioi é caracterizada pela ausência de propágulos vegetativos, margens bastante ciliadas, apotécios eciliados a ciliados, ascósporos menores que $25,0 \mu \mathrm{m}$ compr. e pelos conídios filiformes curto ou baciliformes. Conforme Fleig (1997), Ribeiro (1998) e Eliasaro (2001) apontaram, o grupo de espécies associado à $P$. wainioi trata-se de um dos mais confusos devido ao número de espécies com características muito similares encontrados.

A princípio, antes da análise do material tipo da espécie, cogitou-se que os espécimes do litoral pudessem se tratar de uma das espécies próximas à $P$. wainioi. Os principais caracteres que levaram a dúvida foram a ausência de cílios nos apotécios e os conídios relativamente menores em média (5,0-7,5, raramente até $9,0 \mu \mathrm{m}$ ) do que os mencionados na literatura (cujas medidas em geral variam de. 6,0-11,0 a 9,0-12,5 $\mu \mathrm{m}$ compr.) para $P$. wainioi por Fleig (1997), Ribeiro (1998) e Spielmann (2005).

Historicamente, espécimes de P.wainioi haviam sido tratados por Vainio (1890) como sendo de Parmelia proboscidea Taylor, um equívoco de identificação também seguido por Lynge (1914), e comentado por Hale (1960). Ainda segundo Hale (1965), A. L. Smith sabia que o nome $P$. proboscidea era um sinônimo de $P$. crinita Acharius, propondo então o nome $P$. wainii A. L. Smith para os espécimes erroneamente identificados por Vainio e que pertenciam na verdade a uma espécie desconhecida à época.

Adescrição de Vainio (1890) citou apotécios eciliados e conídios muito pequenos (até $5,0 \mu \mathrm{m}$ ), tais como o material visto aqui. Donha (2005) mencionou conídios quase iguais aos vistos aqui (5,0-8,0 $\mu \mathrm{m}$ compr.), além de citar apotécios raramente ciliados e protolobulados. As descrições de Eliasaro (2001) e de Donha (2005) para $P$. wainioi são as mais semelhantes em geral ao material estudado aqui.

Segundo alguns autores (Fleig 1997, Ribeiro 1998, Eliasaro 2001, Donha 2005), os apotécios de P. wainioi apresentam com frequência cílios, mas nenhum dos espécimes do litoral apresentou este tipo de ornamentação, que é uma diferença normalmente empregada para a separação de várias espécies dentro do gênero Parmotrema.

A análise do material tipo de $P$. wainioi elucidou o fato de que os espécimes de Smith são como os examinados no litoral paulista (i.e., de apotécios eciliados). Com a análise do material tipo, descobriu-se que, de forma semelhante à $P$. subrugatum, os apotécios de $P$. wainioi precisam atingir um determinado estágio de maturação em que desenvolvam pequenos lóbulos. É a partir destes onde por fim surgem os cílios (ao invés de diretamente da margem do anfitécio), caracterizando o surgimento destes como ocasional e condicional nos apotécios destas duas espécies. Assim sendo, talos de ambas as espécies podem ser encontrados com apotécios eciliados, parcialmente ou quase todos ciliados.

Talos de $P$. wainioi têm margem inconstantemente sublacinulada, sem lacínulas regulares como as que ocorrem em $P$. conidiarcuatum ou em talos desenvolvidos de P. subrugatum (Krempelhuber) Hale. Diferente do que ocorre em $P$. subrugatum, a margem inferior de $P$. wainioi é marrom, ficando creme apenas em lobos com apotécios.

Hale (1965) e Fleig (1997) mencionam a presença de pigmento alaranjado $\mathrm{K}+$ vermelho escuro em manchas dispersas na medula, visto aqui em alguns espécimes em áreas velhas ou às vezes embaixo do himênio de apotécios mais velhos. Não foi possível localizar manchas no tipo de $P$. wainioi, pois o talo está com a estrutura do córtex bastante preservada (onde a medula está exposta ainda branca ou apenas suja) e para tanto seria necessário danificar seriamente o material.

Fleig (1997) e Eliasaro (2001) citaram que parte dos cílios em $P$. wainioi apresenta pigmento $\mathrm{K}+$, podendo ser identificados pela coloração diferente dos demais (alaranjados segundo Fleig). Entretanto, não foram encontrados cílios pigmentados nos espécimes estudados aqui, incluindo o tipo.

Fleig (1997) discorreu sobre a variedade morfológica encontrada em seus espécimes de $P$. wainioi, propondo três espécies como sinônimos Ao estudar um espécime saxícola de $P$. brasiliensis Hale com parte do talo exposta ao sol e outra sombreada, a autora percebeu características que identificavam cada parte respectivamente aos materiais tipos de $P$. brasiliensis e de $P$. wainioi.

A descrição original de $P$. brasiliensis (Hale 1990) cita uma espécie saxícola, de talo membranáceo, com apotécios perfurados e os menores ascósporos registrados para espécies contendo ácido alectorônico medular (14,0-15,0 $\mu \mathrm{m}$ compr.). Apesar da sinonimização com P. wainioi, Fleig (1997) mencionou várias peculiaridades notadas nos indivíduos saxícolas que diferiam das encontradas nos corticícolas, afirmando ter encontrado no material tipo de $P$. brasiliensis ascósporos 13,0$18,0 \mu \mathrm{m}$, e conídios ainda maiores $(9,0-10,5 \mu \mathrm{m}$ compr.) que os mencionados por Hale. 
Eliasaro (2001) citou espécimes de P. wainioi com ascósporos menores que os encontrados nas demais descrições (13,0-18,0 $\mu \mathrm{m}$ compr., o mesmo citado por Fleig para o material tipo de $P$. brasiliensis), sendo que o material examinado por Eliasaro é somente saxícola. São ainda necessários mais estudos com espécimes de $P$. wainioi e de $P$. brasiliensis para descobrir se tratam-se realmente de sinônimos ou não, apesar de algumas características em comum.

Com as diferenças citadas por Fleig (1997) é estranho achar que possam ocorrer diferenças drásticas num mesmo espécime apenas pelo grau de exposição, que chegam segundo a autora a diferir o bastante para que diferentes partes se parecerem com os materiais tipos de duas espécies tidas como distintas. Uma suspeita com base neste e em outros trabalhos realizados no litoral (Benatti $\&$ Marcelli 2009a, 2009b, 2010) é que poderiam tratar-se possivelmente de dois talos de espécimes próximas crescendo juntos, tão agregados que dificilmente pudessem ser separados, o que justificaria os comentários.

Talos agregados, onde espécimes com certa similaridade morfológica cresciam lado-a-lado entrelaçados num mesmo substrato foram vistos com outras espécies tais como $P$. achietanum, $P$. dilatatum, P. madilynae, P. tinctorum, dentre outras (Benatti 2005). Parte destes espécimes foi de difícil separação sem o auxílio de lupa, algumas vezes dependendo do uso de artifícios (testes químicos em extremidades opostas e luz ultravioleta para averiguação dos limites da extensão do brilho de substâncias) para serem distintos e separados corretamente.

Mesmo assim alguns poucos espécimes estavam muito unidos e não puderam ser separados sem que a amostra fosse seriamente danificada. A única diferença consistente observada em um espécime parcialmente exposto e parcialmente protegido foi uma variação na espessura (passando de mais coriácea a mais membranácea), mas sem diferenciação quanto a propágulos vegetativos, apotécios, ascósporos e conídios num mesmo talo.

Fleig (1997) citou também talos idênticos ao material tipo de $P$. wainioi e de $P$. chiapensis (Hale) Hale, comentando que foram encontrados "diversos intermediários variando densidade e tamanho de cílios, perfuração de apotécios e a zona marginal inferior mais ou menos branco-matizada". A descrição original de Hale (1965) para P. chiapensis menciona um talo mais delicado e levemente maculado, com apotécios sempre perfurados.

Parmotrema pseudobreviciliatum Adler, Elix \& Hale também foi proposta como sinônimo de $P$. wainioi por Fleig (1997) devido a espécimes identificados com este nome originários dos estados de GO e RJ não apresentarem diferenças objetivas comparados ao material de $P$. wainioi do estado do RS.

Fleig (1997) citou que alguns espécimes de $P$. pseudobreviciliatum se pareciam com espécimes menos ciliados e depauperados de $P$. wainioi, e ainda vários intermediários. A descrição original de P. pseudobreviciliatum (Adler 1989) cita apotécios sempre perfurados como $P$. chiapensis, e que a espécie é saxícola. Outros apontamentos sobre estas e outras espécies com características aproximadas de $P$. wainioi podem ser encontrados em Fleig (1997).

Parmotrema maraense Hale pode ser diferenciada pelos cílios mais curtos (0,5-1,5 mm compr.), apotécios sempre ciliados, lado de baixo mais rizinado com rizinas mais curtas (0,5-1,0 mm compr.) e pelo tamanho maior dos ascósporos (28,0-30,0 $\mu \mathrm{m}$ compr., epispório 3,0 $\mu \mathrm{m})$. Pela descrição de Hale (1990), é possível entender que a medula é mais frequentemente pigmentada na parte inferior do que as manchas dispersas observadas aqui.

Parmotrema subrugatum (Krempelhuber) Hale pode ser diferenciada pelas lacínulas marginais e apicais regulares e subcanaliculadas, margem inferior majoritariamente branca, ascósporos bem maiores (25,0-40,0 $\mu \mathrm{m}$ compr.) e pelos conídios curtos $(4,0-$ $6,0 \mu \mathrm{m}$ compr.) geralmente unciformes (ver comentários em P. subrugatum).

Agradecimentos - Os autores agradecem à assessoria pelas contribuições e revisão do trabalho e ao Conselho Nacional de Desenvolvimento Científico e Tecnológico (CNPq) pelas bolsas de mestrado e de pesquisa concedidas, respectivamente, ao segundo e primeiro autores.

\section{Referências bibliográficas}

ADLER, M.T. 1989. Two new species in Parmeliaceae (Lichenized Ascomycotina) and new records for Argentina. Mycotaxon 35:399-404.

ASAHINA, Y. \& SHIBATA, S. 1954. Chemistry of lichen substances. Japan Society for the Promotion of Science. Ueno, Tóquio.

AWASTHI, D.D. 1976. Lichen genus Parmelia in India I subgenera Parmelia and Amphigymnia. Biological Memoirs 1:155-229.

BENATTI, M.N. 2005. Os gêneros Canomaculina, Parmotrema e Rimelia (Parmeliaceae, Ascomycetes) no litoral centro-sul do Estado de São Paulo. Dissertação de mestrado, Instituto de Botânica, São Paulo.

BENATTI, M.N. \& MARCELLI, M.P. 2007. Gêneros de fungos liquenizados dos manguezais do Sul-Sudeste do Brasil, com enfoque no manguezal do Rio Itanhaém, Estado de São Paulo. Acta Botanica Brasilica 21:863-878. 
BENATTI, M.N. \& MARCELLI, M.P. 2009a. Espécies de Parmotrema (Parmeliaceae, Ascomycota) do litoral centro-sul do Estado de São Paulo, Brasil I. Grupos químicos girofórico e lecanórico. Acta Botanica Brasilica 23:1013-1026.

BENATTI, M.N. \& MARCELLI, M.P. 2009b. Espécies de Parmotrema (Parmeliaceae, Ascomycetes liquenizados) com medula pigmentada do litoral centro-sul do Estado de São Paulo. Hoehena 36: 597-612.

BENATTI, M.N. \& MARCELLI, M.P. 2010. Espécies de Parmotrema (Parmeliaceae, Ascomycota) do litoral centro-sul do Estado de São Paulo III. Grupos químicos equinocárpico e stíctico. Acta Botanica Brasilica 24: 304-321.

BENATTI, M.N., MARCELLI, M.P. \& ELIX, J.A. 2010. Two new species of the Parmotrema subrugatum group from the coast of São Paulo State, southeastern Brazil. Mycotaxon 112:377-388.

BRODO, I.M., SHARNOFF, S.D. \& SHARNOFF, S. 2001. Lichens of North America. Yale University Press, New Haven \& London.

BUNGARTZ, F. 2001. Analysis of lichen substances. Em http://ces.asu.edu/ASULichens/plb 400/laboratory/ chemistry/tlc.html (acesso em 10/2004).

CANÊZ, L.S. 2005. A família Parmeliaceae na localidade de Fazenda da Estrela, Município de Vacaria, Rio Grande do Sul, Brasil. Dissertação de mestrado, Instituto de Botânica, São Paulo.

DODGE, C.W. 1959. Some lichens of tropical Africa III. Parmeliaceae. Annals of the Missouri Botanical Garden 46:39-193.

DONHA, C.G. 2005. Os gêneros Canomaculina, Parmotrema e Rimelia (Ascomycota Liquenizados) na Área de Proteção Ambiental de Guaraqueçaba, Paraná, Brasil. Dissertação de mestrado, Universidade Federal do Paraná, Curitiba.

ELIASARO, S. 2001. Estudio taxonomico y floristico sobre las Parmeliaceae sensu stricto (Ascomycota liquenizados) del Segundo Planalto del Estado de Paraná, Brasil. Tese de doutorado, Facultad de Ciencias Exactas y Naturales, Universidad de Buenos Aires, Buenos Aires.

ELIASARO, S. \& DONHA, C.G. 2003. The genera Canomaculina and Parmotrema (Parmeliaceae, lichenized Ascomycota) in Curitiba, Paraná State, Brazil. Revista Brasileira de Botânica 26: 239-247.

ELIX, J.A. 1994. Parmotrema. In Flora of Australia, Lichens. Introduction, Lecanorales 2. (A.E. Orchard \& C. Grgurinovic, eds.). Australia Government Publishing Service, Canberra, v.55, p.140-162.

FEUERER, T.E. (ED.). 2005. Checklists of lichens and lichenicolous fungi. Versão I Junho de 2006. In http:// www.checklists.de (acesso em 09/2005).
FINK, B. 1905. How to collect and study lichens. The Bryologist 8:22-27.

FLEIG, M. 1997. Os gêneros Parmotrema, Rimelia e Rimeliella (Lichenes-Ascomycota, Parmeliaceae) no Rio Grande do Sul, Brasil. Tese de doutorado, Universidade de São Paulo, São Paulo.

GALLOWAY, D.J. 1985. Flora of New Zealand - lichens. Government Printer, Wellington.

GALLOWAY, D.J. 2007. Flora of New Zealand Lichens. Revised $2^{\text {nd }}$ edition including lichen-forming and lichenicolous fungi. Manaaki Whenua Press, Lincoln, New Zealand, v. 1 and 2.

GALLOWAY, D.J. \& QUILHOT, W. 1998. Checklist of Chilean lichen-forming and lichenicolous fungi. Gayana Botanica 55:111-185.

HALE, M.E. 1959. New or interesting species of Parmelia from North and Tropical America. The Bryologist 62:123-132.

HALE, M.E. 1960. A revision of the South American species of Parmelia determined by Lynge. Contributions from the United States National Herbarium 36:1-41.

HALE, M.E. 1965. A Monograph of the Parmelia subgenus Amphigymnia. Contributions from the United States National Herbarium 36:193-358.

HALE, M.E. 1973. New Parmeliae (lichenes) from Africa 2. Phytologia 27:1-6.

HALE, M.E. 1979. How to know the lichens. The PicturedKey Nature Series. WM. C. Brown Company Publishers, Dubuque.

HALE, M.E. 1990. New species of Parmotrema (Ascomycotina: Parmeliaceae) from Tropical America. Bibliotheca Lichenologica 38:109-119.

HUNECK, S. \& YOSHIMURA, I. 1996. Identification of Lichen Substances. Springer-Verlag, Berlin.

JUNGBLUTH, P. 2006. A família Parmeliaceae (fungos liquenizados) em fragmentos de cerrados do Estado de São Paulo. Dissertação de mestrado, Instituto de Botânica, São Paulo.

KROG, H. 1991. Lichenological observations in low montane rainforests of eastern Tanzania. In Tropical lichens: their systematic, conservation, and ecology (D.J. Galloway, ed.). The Systematics Association Special Volume, Clarendon Press, Oxford, p.85-94.

KROG, H. \& SWINSCOW, T.D.V. 1981. Parmelia subgenus Amphigymnia (lichens) in East Africa. Bulletin of British Museum of Natural History (Botany) 9:143-231.

KUROKAWA, S. \& LAI, M.J. 2001. Parmelioid lichen genera and species in Taiwan. Mycotaxon 77:225-284.

KUROKAWA, S. \& MOON, K-H. 1998. Three new species and a new combination in Parmotrema (Parmeliaceae). Bulletin of the Botanical Garden of Toyama 3:17-23.

LOUWHOFF, S.H.J.J. \& ELIX, J.A. 1999. Parmotrema and allied lichen genera in Papua New Guinea. Bibliotheca Lichenologica 73:1-152. 
LYNGE, B. 1914. Die Flechten der ersten Regnellschen Expedition. Die Gattungen Pseudoparmelia gen. nov. und Parmelia Ach. Arkiv för Botanik 13:1-172.

MARCELLI, M.P. 2004. Checklist of lichens and lichenicolous fungi of Brazil. Version 1: June 2004. http:// www.biologie.uni-hamburg.de/checklists/brazil_l.htm (acesso em 10/2004).

MARCELLI, M.P., BENATTI, M.N. \& ELIX, J.A. 2008. New species of Parmotrema containing protocetraric or stictic acids from the coast of São Paulo State, southeastern Brazil. Mycotaxon 105:235-248.

MARCELLI, M.P., BENATTI, M.N. \& ELIX, J.A. 2010. Two new species of Parmotrema containing alectoronic acid from the coast of São Paulo State, southeastern Brazil. Mycotaxon 115:73-81.

NASH III, T.H. \& ELIX, J.A. 2002. Parmotrema. In Lichen flora of the greater Sonoran Desert Region (T.H. Nash III, B.D. Ryan, C. Gries \& F. Bungartz, eds.). Lichens Unlimited, Arizona State University, Tempe, v.1, p.318-329.

ORANGE, A., JAMES, P.W. \& WHITE, F.J. 2001. Microchemical methods for the identification of lichens. The British Lichen Society, London.

OSORIO, H.S. 1972. Contribution to the lichen flora of Uruguai VII. A preliminary catalogue. Comunicaciones Botánicas del Museo de Historia Natural de Montevideo 4:1-46.

OSORIO, H.S. 1977. Contribution to the lichen flora of Brazil III. Lichens from western Paraná. Acta Biologica Paranaense 6:3-7.

OSORIO, H.S. 1992. Contributions to the lichen flora of Uruguay XXV. Lichens from Sierra San Miguel, Rocha Department. Boletín de la Sociedad Argentina de Botánica 28:37-40.
PEREIRA, W.R. \& MARCELLI, M.P. 1989 (1991). Liquens da Reserva Biológica do Alto da Serra de Paranapiacaba. Acta Botanica Brasilica 3:89-94.

RIBEIRO, C.H. 1998. A família Parmeliaceae (Ascomycota liquenizados) em regiões montanhosas dos Estados de Minas Gerais, Rio de Janeiro e São Paulo. Dissertação de Mestrado, Universidade de São Paulo, São Paulo.

SIPMAN, H.J.M. 2000. Checklist of the lichenized fungi of the Guianas. http:/www.mnh.si.edu/ biodiversity/bdg/ guilich3.html (acesso em 07/2005).

SIPMAN, H.J.M. 2004. Mason Hale's key to Parmotrema, revised edition: key to wide-lobed parmelioid species occurring in Tropical America (genera Canomaculina, Parmotrema, Rimelia, Rimeliella). http://www.bgbm. org/sipman/keys/neoparmo.htm (acesso em 07/2005).

SPIELMANN, A.A. \& MARCELLI, M.P. 2009. Parmotrema s.l. (Parmeliaceae, lichenized Ascomycota) from Serra Geral slopes in central Rio Grande do Sul State, Brazil. Hoehnea 36:551-595.

SWINSCOW, T.D.V. \& KROG, H. 1988. Macrolichens of East Africa. British Museum of Natural History, London.

VAINIO, E.A. 1890. Étude sur la classification naturelle et la morphologie des Lichens du Brésil, pars prima. Acta Societatis pro Fauna et Flora Fennica 7:1-247.

WALKER, J.W. \& JAMES, P.W. 1980. A revised guide to microchemical techniques for the identification of lichen products. Bulletin of the British Lichen Society 46:13-29.

WHITE, F.J. \& JAMES, P.W. 1985. A new guide to microchemical techniques for the identification of lichen substances. Bulletin of the British Lichen Society 57:1-41. 


\section{Este texto sofreu a seguinte alteração em 13/10/2011 por solicitação da editora Solange C. Mazzoni-Viveiros:}

\section{Revista Brasileira de Botânica}

2011; 34(3): 261

No rodapé, onde se lê / In the footnote, where it reads:

1. Parte da tese de doutorado do segundo autor, Programa de Pós-Graduação em Biodiversidade Vegetal e Meio Ambiente, Instituto de Botânica, SP, Brasil.

Leia-se / It should read:

1. Parte da dissertação de mestrado do segundo autor, Programa de Pós-Graduação em Biodiversidade Vegetal e Meio Ambiente, Instituto de Botânica, SP, Brasil.

2011; 34(3): 262

Onde se lê / Where it reads:

$\ldots \mathrm{K}-, \mathrm{C}-, \mathrm{KC}+$ róseo (às vezes $\rightarrow$ alaranjado claro), $\mathrm{P}$ - e UV+ verde-azulado (ácido alectorônico).

Leia-se / It should read:

$\ldots \mathrm{K}-, \mathrm{C}-, \mathrm{KC}+$ róseo (às vezes $\rightarrow$ alaranjado claro), $\mathrm{P}-\mathrm{e} \mathrm{UV}+$ verde-azulado (ácido alectorônico).

2011; 34(3): 270

Onde se lê / Where it reads: UV- , leia-se / it should read: UV- 